\title{
Psychological Universals: What Are They and How Can We Know?
}

\author{
Ara Norenzayan and Steven J. Heine \\ University of British Columbia
}

\begin{abstract}
Psychological universals, or core mental attributes shared by humans everywhere, are a foundational postulate of psychology, yet explicit analysis of how to identify such universals is lacking. This article offers a conceptual and methodological framework to guide the investigation of genuine universals through empirical analysis of psychological patterns across cultures. Issues of cross-cultural generalizability of psychological processes and 3 cross-cultural research strategies to probe universals are considered. Four distinct levels of hierarchically organized universals are possible: From strongest to weakest claims for universality, they are accessibility universals, functional universals, existential universals, and nonuniversals. Finally, universals are examined in relation to the questions of levels of analysis, evolutionary explanations of psychological processes, and management of cross-cultural relations.
\end{abstract}

Keywords: universals, cross-cultural differences, cross-cultural methods, evolutionary psychology

There are two statements about human beings that are true: that all human beings are alike, and that all are different. On those two facts all human wisdom is founded.

-Mark Van Doren, American poet (1894-1972)

Human psychological universals are core mental attributes that are shared at some conceptual level by all or nearly all non-braindamaged adult human beings across cultures. The assumption of human universals is a foundational postulate of psychology, and as such, a rich understanding about how we can consider universality in psychological phenomena is of great importance to the field. In this article, we bring together insights and observations from the emerging field of cultural psychology to bear on the questions of psychological universals that are of concern to most fields of psychology: what psychological universals are and are not, what standards of evidence there are to support their occurrence and degree of generality, what their types or levels are, and what research strategies are available to probe them.

Cultures are to some degree adaptive responses to their environments (D. Cohen, 2001), and unlike most other species, human beings occupy vastly different ecological niches demanding different sociocultural arrangements (Boyd \& Silk, 2003; Diamond, 1997; Edgerton, 1971). Humans are also endowed with cognitive

Ara Norenzayan and Steven J. Heine, Department of Psychology, University of British Columbia.

The writing of this article was supported by grants from the Social Sciences and Humanities Research Council of Canada (SSHRC; 4102004-0197) and the University of British Columbia Hampton Fund (12R41699) to Ara Norenzayan and by grants from the National Institute of Mental Health (R01 MH060155-01A2) and SSHRC (410-2004-0795) to Steven J. Heine. We thank Richard Nisbett, Jeffrey Sanchez-Burks, and Mark Schaller for their thoughtful comments regarding an earlier version of this article.

Correspondence concerning this article should be addressed to Ara Norenzayan, Department of Psychology, University of British Columbia, 2136 West Mall, Vancouver, British Columbia V6T 1Z4, Canada, E-mail: ara@psych.ubc.ca capacities for massive cultural transmission that favors ingroup members (Henrich \& Boyd, 1998) and enables them to consider the perspectives of fellow group members (Dunbar, 1992; Tomasello, Kruger, \& Ratner, 1993). From a game-theoretical point of view, this social nature of our species renders the outcomes of any strategy that an individual pursues dependent on what his or her group members opt to do. This mutual interdependence between individual and ingroup member leads to multiple equilibria for any social system, which further fuels the engines of cultural diversity (D. Cohen, 2001; Fiske, 2000). This combination of ecological variability, ingroup-biased cultural diffusion, and multiple equilibria have led to vast degrees of sociocultural diversity throughout history.

The existence of cultural diversity poses a great challenge to psychology: The discovery of genuine psychological universals entails the generalization of psychological findings across disparate populations having different ecologies, languages, belief systems, and social practices. Moreover, psychological phenomena often reflect the interaction of innate psychological primitives with sociocultural inputs, yielding contingent universals of an "if-then" sort (e.g., cooperate if neighbors are cooperative, otherwise defect; see Kenrick, Li, \& Butner, 2003). Such generalizations demand comparative studies based on rigorous criteria for universality. Yet psychological universals have largely been a neglected topic of explicit analysis in psychology.

\section{Past Considerations of Universals in Anthropology}

Although human universals have been largely overlooked in psychology, they have been examined in linguistics (e.g., Comrie, 1981; Slobin, 1978) and biology (e.g., Alexander, 1979; Dobzhansky, 1962). However, universals have been explored and debated the most within anthropology since the modern era of that field first emerged. One goal of the anthropological enterprise has been to explore and explain the vast degrees of diversity of human natures across the planet (e.g., Benedict, 1934). This explicit focus on investigating diversity came with a cautious awareness about 
the pitfalls of generalizing beyond one's samples. We suggest that the anthropological literature of the last 100 years renders the question of human universals both urgent and difficult. It is urgent in that the vast array of diverse human potentials uncovered in ethnographies from around the world behooves us to consider what features unite humankind. The question is difficult because identifying something as universal amidst an array of diverse instantiations requires one to make distinctions between the concrete, particular manifestations that can be observed in behavior and the abstract, underlying universals that have given rise to those behaviors. This distinction, challenging at the best of times, has provided no shortage of controversy and debate (e.g., Ekman, 1994, in response to Russell, 1994; Geertz, 1973; Shweder, 1991; Spiro, 1987).

Relatively early in the discipline's history, there were attempts by many anthropologists to document universals in human nature. Clark Wissler (1923), for example, constructed a universal taxonomy that reflected hypothesized human needs by which anthropologists could organize the diverse particulars that they encountered in their expeditions. Similar taxonomies were developed and refined as a growing chorus considered the question of what features of human nature were universal (e.g., Kluckhohn, 1953; Levi-Strauss, 1969; Malinowski, 1944; Murdock, 1945). What became apparent from these early efforts was a distinction between categories of universals, such as religion or kinship, and their varied content, such as beliefs in reincarnation and matrilineal descent. Indeed, the sheer range of diversity in the content of human activity revealed through the growing ethnographic database left little dispute that this was an inappropriate level at which universals could reliably be found. However, later efforts (e.g., Berlin \& Kay, 1969; Goodenough, 1970) demonstrated that certain kinds of cognitive content could indeed embody universals. Recent developments in cognitive anthropology and developmental psychology have further buttressed the case for a striking degree of universality in the content of thought and behavior (e.g., Atran, 1998; Avis \& Harris, 1991; Boyer, 1994; see especially Hirschfeld \& Gelman, 1994).

The most extensive recent effort to catalogue human universals was that by Donald Brown (1991), who constructed a list of hundreds of characteristics, incorporating both categories (e.g., marriage, rituals, language) and content (e.g., fear of snakes, coyness displays, having color terms for "black" and "white") that are common to people everywhere. These efforts to discern and taxonomize the universal human, or the consensus gentium (Geertz, 1973), have been highly controversial throughout the history of anthropology. Some have questioned whether interesting human universals really exist (e.g., Benedict, 1934; Mead, 1975), and others have argued that such efforts to identify the lowest common denominator of humankind are either misguided or of dubious value (e.g., Geertz, 1973). More recently, a growing number of voices in cultural anthropology have adopted a poststructuralist perspective, emphasizing the fluidity and ambiguity of culture. There is a marked skepticism in this view toward generalizing from the individual level to the cultural level, let alone generalizing to the level of what is universally human (e.g., Bourdieu, 1977; Brightman, 1995; Clifford \& Markus, 1986).

\section{Past Considerations of Universals in Psychology}

In contrast to the long history of positing and debating universals in anthropology, the question of whether a given psychological phenomenon is universal has rarely been considered explicitly throughout much of psychology's history, with a few notable exceptions (e.g., etics and emics, Berry, 1969; sex differences in attraction, Buss, 1989; violence, Daly \& Wilson, 1988; facial expressions, Ekman, Sorenson, \& Friesen, 1969; motives, Klineberg, 1954; social behavior, Pepitone \& Triandis, 1987; Triandis, 1978; see also Lonner, 1985). We suggest that the question of universality is so often neglected because much of psychology has maintained the implicit assumption that its objects of investigation were de facto universals. This unstated assumption of universality, or "psychic unity" (e.g., Murdock, 1945), can be discerned from two observations about the field of psychology. First, the origins of psychology have been profoundly influenced by biology (Benjamin, 1988). This biological basis of the field has led to an assumption of psychological universals in at least two respects: Much research on the biological basis of human psychology is conducted analogically in other species. This is done with the idea that psychological mechanisms in other species can speak to human psychological functioning. However, if we begin with the view that humans in one culture share psychological mechanisms with other species, it follows that these same psychological mechanisms are assumed to be shared universally within humans themselves. Furthermore, to the extent that psychology is conceived to be grounded in biology, it inherits the theoretical foundation of evolutionary theory as well (Barkow, Cosmides, \& Tooby, 1992; Pinker, 1997). Because evolutionary reasoning hinges on the assumption of a shared species-wide genome, this theoretical foundation encourages psychologists to accept psychic unity as a given. In these ways, the biological heritage of psychology presupposes that psychological mechanisms are universal.

Second, the cognitive revolution provided another framework from which to understand human thought, and this framework also presupposes universality. Cognitive science has relied heavily on the idea that the human mind is analogous to the computer (Block, 1995). This metaphor makes explicit the perspective that brain hardware gives rise to universal software, or psychological processes. In this model, output can be observed in beliefs, values, and behaviors, and these could vary endlessly across cultures and historical periods given the radically different inputs generated by the diverse social, political, and economic environments in which people live. Beneath this shallow surface of variability of mental content rests the easily discernible deep structure of universal psychology. Indeed, individual differences, let alone cultural differences, are rarely considered when the computer metaphor is invoked.

\section{Universals and the Restricted Database of Psychology}

The assumption of universality in psychology is perhaps most evident when we consider the discipline's sampling methodology. Unlike many of the other social sciences (e.g., anthropology, geography, political science, and sociology) psychologists tend not to concern themselves with questions of generalizability of their samples to populations at large except with respect to populations that might deviate from the normal and universal mind, such as patients with brain injuries or with clinical disorders. The sampling 
method that has become standard in cognitive, social, and personality and some research in clinical psychology is to recruit participants from undergraduate psychology classes and to make inferences about the human mind on the basis of these participants. This critique is not new (e.g., Gergen, 1973; Sears, 1986). Yet this method is rarely called into question (with some important recent exceptions, Medin \& Atran, 2004; Rozin, 2001), underscoring how most psychologists implicitly assume that the findings that derive from a particular sample, bounded by context, historical time, and social class, would generalize to other contexts.

Exacerbating this issue of nonrepresentative sampling is an issue of uneven geographical representation in research. A recent survey of all the published papers in the history of the Journal of Personality and Social Psychology, the flagship journal of social and personality psychology, revealed that $92 \%$ of the papers originated in the United States and Canada, and a full 99\% emerged from Western countries (Quinones-Vidal, Lopez-Garcia, Penaranda-Ortega, \& Tortosa-Gil, 2004). This pattern is not unique to social psychology, however, and if anything, is exacerbated in other fields of psychology. An analysis of the proportion of major journal articles in psychology from 1994 to 2002 that included the keyword "culture" found that the term appeared in only $1.2 \%$ of the articles in major cognitive and experimental psychology journals, $3.1 \%$ of major clinical psychology journals, $4.3 \%$ of major developmental psychology journals, and $4.8 \%$ of major social psychology journals (Hansen, 2005). Thus, many psychologists have not been studying human nature-they have been investigating the nature of educated, middle-class, young adult Westerners (or the children of such people). This sampling issue is especially problematic given that Western middle-class populations from which most psychology samples are derived, far from being typical of the world, happen to represent a cultural anomaly in that they are unusually individualistic, affluent, secular, low context, analytic, and self-enhancing with respect to the rest of the world (Fiske, Kitayama, Markus, \& Nisbett, 1998; Lipset, 1996; Triandis, 1995). It is reasonable to restrict our investigations to the most convenient samples if the processes that we are studying are known to reflect a common, underlying human nature. However, this convenience bears a substantial cost if we wish to question whether psychological phenomena are universal. The bedrock of the psychological database, consisting of cumulating layers of findings from Western middle-class collegeeducated young adults and their young children, prevents us from testing this assumption.

Assuming universals from a restricted database is not just a theoretical problem for psychology. It is an empirical one too. The past two decades have witnessed an explosion of research on cultural psychology. Much of this research has identified just how poorly many of our theories and findings generalize to other cultural contexts. This observed cultural diversity has not been restricted to a narrow subset of marginal phenomena; rather it cuts across the central theories and findings of psychology. For example, some phenomena that are less evident or appear in significantly divergent forms in other cultures include, from cognitive psychology, memory for and categorization of focal colors (e.g., Roberson, Davidoff, Davies, \& Shapiro, 2004; Roberson, Davies, \& Davidoff, 2000), spatial reasoning (Levinson, 1996), certain aspects of category-based inductive reasoning (Bailenson, Shum, Atran, Medin, \& Coley, 2002; Medin \& Atran, 2004), some perceptual illusions (e.g., Segall, Campbell, \& Herskovits, 1963), perceptual habits (e.g., Masuda \& Nisbett, 2001), habitual strate- gies for reasoning and categorization (e.g., Nisbett, Peng, Choi, \& Norenzayan, 2001; Norenzayan, in press), the relation between thinking and speaking (e.g., Kim, 2002), and certain aspects of numerical reasoning (Gordon, 2004; K. F. Miller \& Paredes, 1996); from judgment and decision making, preferred decisions in the ultimatum game (e.g., Henrich et al., in press) and risk preferences in decision making (Hsee \& Weber, 1999); from social and personality psychology, independent self-concepts (e.g., Markus \& Kitayama, 1991), the similarity-attraction effect (e.g., Heine \& Renshaw, 2002), motivations for uniqueness (e.g., Kim \& Markus, 1999), approach-avoidance motivations (e.g., Elliot, Chirkov, Kim, \& Sheldon, 2001), the fundamental attribution error (e.g., Choi \& Nisbett, 1998; J. G. Miller, 1984; Morris \& Peng, 1994; Norenzayan \& Nisbett, 2000), self-enhancing motivations (e.g., Heine, Lehman, Markus, \& Kitayama, 1999), predilections for violence in response to insults (e.g., Nisbett \& Cohen, 1996), high subjective well-being and positive affect (e.g., Diener, Diener, \& Diener, 1995; Kitayama, Markus, \& Kurokawa, 2000), feelings of control (e.g., Morling, Kitayama, \& Miyamoto, 2002), communication styles (e.g., Sanchez-Burks et al., 2003), consistent selfviews (e.g., Suh, 2002), and emotion (e.g., Elfenbein \& Ambady, 2002; Mesquita, 2001); from clinical psychology, the prevalence of major depression (Weissman et al., 1996), depression as centered on negative mood (e.g., Kleinman, 1982; Ryder, 2004), social anxiety (Okazaki, 1997), the prevalence of eating disorders such as anorexia nervosa and bulimia (e.g., Lee, 1995), and a number of other indigenous syndromes that have not yet received much attention in the West (e.g., agonias among Azoreans, S. James, 2002; ataque de nervios among Latino populations, Liebowitz, Salmán, Jusino, \& Garfinkel, 1994; hikikomori among Japanese, Masataka, 2002; and whakama among the Maori, Sachdev, 1990); and from developmental psychology, the noun bias in language learning (Tardif, 1996), moral reasoning (e.g., A. B. Cohen \& Rozin, 2001; J. G. Miller \& Bersoff, 1992; Shweder, Much, Mahapatra, \& Park, 1997), the prevalence of different attachment styles (e.g., Grossmann, Grossmann, Spangler, Suess, \& Unzer, 1985), and the tumultuousness and violence associated with adolescence, Schlegel \& Barry, 1991). This growing body of research exploring cultural diversity in psychology urges the field to take a step back to reconsider how we can conceptualize whether psychological phenomena are universal.

\section{The Need for Methodological Criteria for Investigating Psychological Universals}

The relatively long history of debating human universals in the anthropological literature has greatly informed the investigation of psychological universals (for examples, see Atran \& Norenzayan, 2004; Berlin, 1992; Berlin \& Kay, 1969; D. Brown, 1991; Daly \& Wilson, 1988; Medin \& Atran, 1999). Nevertheless, there are enough differences between the fields of anthropology and psychology to warrant distinct (but hopefully converging) efforts to develop methods that can facilitate the search for psychological universals. We identify three reasons for this. First is the issue of geographical limitations. The investigation of universals will be indebted to the methodical documentation of cultural diversity compiled by the pioneering efforts of anthropologists throughout the 20th century. In particular, the Human Relations Area Files database is of considerable utility for questioning what is univer- 
sal, although conclusions are limited by the reliability and validity of the individual ethnographies. However, the extensive coverage of the anthropological database is something that psychology may strive toward yet not fully attain. It is unrealistic to expect many psychologists to regularly launch the same kind of ambitious enterprises to explore the varieties of psychological experiences in all known cultures on the planet. Thus, the psychological database will likely remain relatively impoverished in terms of the numbers of cultures explored compared with that amassed through a century of ethnographies. Nevertheless, this does not mean that questions of universals cannot be empirically tested. It suggests the need to adopt strategies that can inform these questions in the absence of the rich and extensive database covering many of the world's cultures.

A second key difference between psychology and anthropology is that psychology's object of study, the workings of individual minds, is different from that of anthropology, which is to investigate human lives in their broader ecological contexts. A consideration of psychological universals requires guidelines that can inform investigations of processes that are traditionally the focus of psychological research: attention, memory, self-concepts, mental health, cognitive strategies, decision rules, emotional programs, perceptions, motives, personality structures, language acquisition, causal theories, and other mental representations of the world. In contrast, the question of potential universals in the anthropological sense (for a thorough discussion, see D. Brown, 1991) is targeted at a different set of characteristics. These may include family and social structures (governance, kinship relationships), social practices (coming of age rituals, treatment of the dead), and the use of tools (fire, weapons). Whether these are social phenomena that are superorganic and theoretically autonomous from individual minds (e.g., Durkheim, 1915/1965; Geertz, 1973) or, more plausibly, are causally connected social distributions of mental representations and their material effects in a population (e.g., Atran \& Sperber, 1991; Sperber, 1996; see also Boyd \& Richerson, 1985), universals at the collective level diverge from psychological universals in important ways. Different objects of study require different standards of evidence: For example, posing questions about cultural practices such as initiation rites and kinship terminology requires different kinds of evidence obtained by participant observation, linguisitic analysis, and data collection at the societal level than does posing questions about psychological phenomena such as cognitive dissonance and loss aversion, which are best approached through controlled experimentation at the individual level.

The third difference between psychology and anthropology reflects the most commonly used methodologies within the two fields. Anthropological data have largely been amassed through qualitative ethnographic methods, whereas psychological data are largely the product of quantitative methods that employ experimental and correlational designs. These methods have their respective strengths and weaknesses but differ regarding issues of sampling, measurement, replicability, experimental control, generalizability, and the richness of the data. The methods are different enough that it is relatively rare for psychologists and anthropologists to consider each other's data. We submit that such cross-fertilization would greatly benefit the study of universals for both fields, provided that psychologists were better able to develop systematic ways of examining their phenomena cross-culturally.
Despite growing interest in psychological universals, there is as of yet no set of agreed upon methodological criteria by which we can consider universals. In the absence of such criteria, researchers have largely relied on appeals to their readers' intuitions as to what kind of data would strengthen the case for universality. It is urgent for the field to consider some guidelines by which research endeavors regarding psychological universals can be facilitated.

In sum, we are proposing that the investigation of psychological universals will benefit from a consideration of strategies that are appropriate for the idiosyncrasies of psychological research. This should include methods by which universals can be investigated without resorting to an exhaustive sampling of every culture of the world, guidelines for investigating questions of universality of psychological phenomena, and data collection efforts that can accommodate the peculiarities of the quantitative methods used by most psychologists.

\section{Research Strategies to Test Hypotheses Regarding Psychological Universals}

Establishing the universality of a phenomenon entails generalizing across diverse populations to humanity or a broad subset thereof (e.g., all adolescents, all adult men, all literate people). ${ }^{1}$ Generalizability across cultures is a special case of the generality of effects across contexts, items, and populations in psychology (Abelson, 1996; Shavelson \& Webb, 1991).

An important initial challenge in this endeavor is the issue of comparability of measures across cultures. That is, cross-cultural comparisons are successful only to the extent that the meaning of the questions and experimental settings are known to be roughly similar across cultures (Pepitone \& Triandis, 1987; Poortinga, 1989; Van de Vijver \& Leung, 1997). Although this issue often defies easy solutions (e.g., Heine, Lehman, Peng, \& Greenholtz, 2002; Peng, Nisbett, \& Wong, 1997), it is a problem that has been addressed with a number of converging strategies available in the cross-cultural literature, including back-translation, emically (locally) derived measurement, multimethod observations, and establishing equivalency of meaning in control conditions (for reviews, see Berry, Poortinga, \& Pandey, 1997; Okazaki \& Sue, 1995; Triandis, 2000). Indeed the research strategies reviewed below reflect the profitable use of such tools.

The generality of effects across cultures can be investigated systematically. We focus on three cross-cultural research strategies that can shed light on claims of universality. The two-cultures approach relies on convergent evidence for a psychological phenomenon in divergent cultural contexts. The three-cultures or triangulation approach achieves the same goal, examining the generality of a phenomenon across two well-defined cultural di-

\footnotetext{
${ }^{1}$ A related generalizability issue in cross-cultural research is whether samples ought to be representative of the cultures they represent. Random sampling, which is infrequent in psychological research, is necessary if researchers wish to draw inferences about population parameters of the cultures of interest (e.g., What is the typical self-esteem level of Japanese people?) However, this is not the goal in most cross-cultural psychological research, which is primarily concerned with the ways by which particular ecological contexts afford psychological tendencies, for example, honor cultures affording aggression in response to insult (Nisbett \& Cohen, 1996).
} 
mensions. Finally, the cross-cultural survey approach is the most powerful in establishing universality, but it comes with its own methodological challenges and is also the costliest of all crosscultural research strategies.

\section{Generalizability Across Two Cultures}

The simplest strategy that encourages claims of universality is to compare two populations that vary greatly on as many theoretically relevant dimensions as possible, such as social practices, philosophical traditions, language, geography, socioeconomic status, literacy, and level of education. The claim of universality is strengthened to the extent that the same psychological process or phenomenon emerges in widely divergent contexts. The more divergent the contexts, the more powerful are the claims of universality.

Consider, as an illustration, studies of children's theory of mind across cultures. At about 4-5 years of age, preschoolers develop an elaborate theory of mind, which entails, among other things, the attribution of beliefs and desires to people and the appreciation that people may have false beliefs (Wellman, 1990). It has been argued that a theory of mind is fundamental to social functioning and may be critically implicated in the human ability for cultural learning (Tomasello et al., 1993).

Studies of children's theory of mind have been conducted among North American and Western European children. Thus a critical question is whether a mentalistic framework for the understanding of human behavior found in Western children is a reflection of Western cultural contexts or a reflection of universal early childhood development. To address this question, Avis and Harris (1991) examined the theory of mind in Baka children. The Baka are a pygmy people who live in the rainforests of southeast Cameroon. They are nonliterate hunter-gatherers with little or no exposure to Western philosophical ideas that may potentially contribute to mentalistic interpretations of human behavior. Thus the Baka and Western children represent sharply divergent cultural contexts.

Avis and Harris (1991) examined the false-belief task, a widely used measure of theory of mind. In this task, children of different ages were invited to move the location of a desirable food from its container to a hiding place in the absence of the adult preparing the food. The children were then asked to predict whether the returning adult would look for the food in the container (the false-belief answer) or the hiding place (the true-belief answer).

The results largely replicated the pattern found among Western children. A majority of older children passed the false belief task, correctly predicting that the adult would approach the empty container and not the hiding place to which the food was moved. A minority of younger children were also systematically correct. Similar to Western children, by age 4-5, Baka children were good at predicting a person's behavior based on that person's beliefs. The fact that a similar mentalistic understanding of behavior emerged at around the same age in sharply divergent cultural contexts strengthens the case that the ability to appreciate false beliefs is a functional universal, largely determined by pancultural processes of human development.

Cross-cultural comparisons of theory of mind reasoning have been sparse and unsystematic. The existing evidence points to both universality and cultural variability (Wellman, Cross, \& Watson,
2001; see also Lillard, 1998, for a discussion of ethnographic accounts of cultural variability). In a recent meta-analysis of theory of mind reasoning across cultures, Wellman et al. (2001) found that the developmental trajectory in children's false belief performance was the same across cultural and linguistic contexts, although cultural variation was found in performance rates at any given age group. No single variable has been identified so far that predicts the cross-cultural differences.

More concerted research is required to reach firm conclusions about the universality of theory of mind reasoning. However Avis and Harris's (1991) study illustrates the power of the two-cultures approach in bolstering a claim for universality (see also Flavell, Zhang, Zou, Dong, \& Qi, 1983, for similar evidence among Chinese children). Cultures that are theoretically maximally divergent on the domain under question yield the most convincing examples of potential universals (e.g., comparing color perception across groups that differ in their color terms, Heider \& Oliver, 1972; but see Roberson et al., 2000, 2004; comparing facial expressions across cultures with minimal shared cultural history and contact with each other, Ekman, Sorenson, \& Friesen, 1969). ${ }^{2}$

Consider a case in which the two-culture strategy fails to corroborate a universality claim of a process in developmental psychology. Carey (1985) proposed an influential argument that children until the age of 10 do not possess a distinct folkbiological understanding; instead, they project their folkpsychological understanding on the natural world. As a result, young children's understanding of biological phenomena is anthropocentric and intertwined with folkpsychological notions. In support of this argument, Carey presented evidence from studies of preschoolers in Cambridge, Massachusetts, indicating that projections of unknown properties from humans are stronger overall than projections from other animals; projections from humans to mammals are stronger than projections from mammals to humans; and most surprisingly, projections from humans to bugs are stronger than from even bees to bugs. Together, these findings suggest that children privilege humans for their inferences about the natural world.

Given that Carey's (1985) evidence comes exclusively from a North American urban population, it is an open question as to whether the Cambridge children's human-centered inferences are reflective of a universal cognitive tendency or a cognitive pattern that is reflective of the unique circumstances of North American middle-class culture. To answer this question, a recent study compared biological reasoning among urban American children and rural Menominee Indian children of northern Wisconsin (Medin \& Atran, 2004). Menomenee children live in contexts that depart considerably from the Cambridge, Massachusetts, cultural milieu. They live in a rural environment in which children are immersed in the natural world of plants and animals at a very early age. The urban American children again made projections that were human centered, by and large replicating Carey's findings. However, contrary to Carey's argument, Menominee children did

\footnotetext{
${ }^{2}$ In contrast, if cultural differences are expected, then comparisons with populations that share background similarities that are not objects of investigation (e.g., Chinese and American undergraduates of similar age, scholastic ability, socioeconomic status, and educational level) are warranted and desirable, because such comparisons eliminate many confounds as potential explanations of the differences.
} 
not privilege humans over other animals. They did not make stronger projections from humans than from other animals, and they did not make stronger projections from humans to mammals or humans to bugs than from mammals to other mammals or from bees to bugs. The researchers argued that urban American children's anthropocentric bias is likely to be a reflection of a particular cultural circumstance-a lack of sufficient exposure to nonhuman species-leading to an impoverished folkbiological domain, rather than a universal tendency in causal understanding. Alternatively, it is conceivable that Menomenee children may start with an anthropocentric framework from an early age, but overcome this tendency through cultural training by the age of 10 . Either way, folk psychology guides folk biology only in the absence of a well-developed folkbiological framework, as they argued to be the case in urban American culture (see also Atran et al., 2001, regarding a similar pattern of results among rural Yucatec Maya children).

As compelling as this explanation for the cultural differences may be, the basic design of the two-cultures strategy makes it difficult to isolate the sociocultural variable that is at the core of the difference, because urban middle-class children in Massachusetts and Menomenee children in northern Wisconsin differ not only in their degree of exposure to the natural world, but in numerous other ways as well. The two-cultures strategy works well as long as findings point to universality, but the very strength of this strategy is its principal weakness when cultural differences are found. The three-cultures strategy, discussed next, addresses this limitation.

\section{Generalizability Across Three Cultures}

The three-cultures or triangulation strategy entails a two-step process (see Bailenson et al., 2002; Medin \& Atran, 2004, for further discussion). In the first step, a psychological phenomenon is examined across two cultures, A and B, that are known to vary on a carefully selected theoretically relevant Dimension 1 . In the second step, a third culture, $\mathrm{C}$, is included that varies on another theoretically relevant Dimension 2 from one of the previous two cultures, A or B. As a result, Cultures A and B would be different on Dimension 1, whereas Cultures B and C would be different on Dimension 2. The goal of this strategy is twofold. First, it facilitates generalization across two maximally different sociocultural contexts or theoretical dimensions that are known to affect psychological processes. Second, should researchers find a cultural difference, this design sheds light on the specific population variable that is implicated in the psychological difference. In this approach, different dimensions of cultural variation are relevant for a given cross-cultural study. In one case, a cultural difference in the availability of a linguistic structure may be most relevant, whereas in another case, the presence or absence of institutions that enforce cooperation may be most relevant. An important task for the researcher, then, is to start with good intuitions or theoretical expectations to guide the careful selection of the most appropriate samples.

Consider studies on category-based induction in folkbiology (Bailenson et al., 2002; Medin \& Atran, 1999; see also Medin \& Atran, 2004). In these studies, the cross-cultural generality of an influential model of category-based induction, the similaritycoverage model (SCM) was explored (Osherson, Smith, Wilkie,
Lopez, \& Shafir, 1990). Two inductive reasoning phenomena predicted by the SCM, similarity and diversity, were examined among American college students and Maya villagers in the Petén region of Guatemala - a small-scale, nonindustrialized, semiliterate society. Given the disproportionate reliance on university student samples in cross-cultural comparisons, this research program is an especially important investigation regarding the generality of psychological phenomena.

In the SCM of inductive inference, the similarity of premises to conclusions predicts the strength of inductive inference (the similarity phenomenon). Thus, given that robins have some unknown property, people feel more certain that sparrows also have that property than that crows have that property. Also, the more diverse the premise categories are, the stronger the inductive inference to a conclusion category that subsumes these premise categories (the diversity phenomenon). Given that white pine and weeping willows get one new disease and river birch and paper birch get another new disease, people reason that the former disease is more likely to affect all trees, because weeping willows and white pine offer better coverage of the tree category. It was found that whereas both North American undergraduates and Maya villagers reasoned based on similarity, only North American undergraduates showed any evidence of reasoning based on diversity.

However this cultural difference is difficult to interpret, given that American undergraduates and Maya villagers differ in myriad ways, including ethnicity, language, education, socioeconomic status, age, and knowledge of the natural environment. Medin and colleagues (e.g., Medin \& Atran, 2004) took the additional step of examining inductions of a third cultural group-American tree experts in suburban Chicago. These tree experts share similar cultural characteristics as college undergraduates but differ mainly in the degree to which they are knowledgeable of the biological world and make daily use of this knowledge. Maya are similar to American tree experts in that they also possess a deep biological knowledge and use it on an everyday basis. However they differ from both American samples in that the Maya have scant exposure to Western philosophical ideas that have shaped Western perceptions of the natural world.

Two types of American tree experts (taxonomists and park maintenance workers) showed a mixture of ecological and diversity reasoning; the amount of ecological reasoning depended on the type of expertise (Proffitt, Coley, \& Medin, 2000). Whereas taxonomists reliably used diversity strategies, park maintenance workers, similar to Maya villagers, reasoned ecologically, showing little evidence of diversity. Ecological justifications of the park maintenance workers centered on the frequency and range of tree distribution, susceptibility and resistance to disease, or mechanisms of disease transmission (Proffitt et al., 2000). The authors concluded that immersion in the biological world is the key factor that affects ecological reasoning, and in the absence of such expertise, people revert to the diversity heuristic.

Finally, a particular strength of the triangulation strategy is that it circumvents what often are circular cultural explanations of behavior (e.g., "U.S. Southern males respond violently to insult because of their Southern culture of honor, which fosters insultrelated violence.") Such circularity arises when cross-cultural researchers fail to isolate and measure the ecological variables of interest, instead choosing a sample that embodies the ecological variable (see Bailenson et al., 2002). In targeting a third sample 
that is culturally similar to one sample but shares the ecological conditions of the other, triangulation sidesteps this circularity problem by disentangling an ecological variable from its conventional population. Consider, for example, inner city men in the U.S. Northeast, who share a culture of honor and a similar ecological milieu as Southern U.S. men (perceptions of scarcity of economic resources, coupled with distrust in state protection and feelings of vulnerability to predation). They are, however, arguably more similar to U.S. Northern men in political and social attitudes and other cultural characteristics. Nevertheless, they would be expected to behave more like Southern U.S. men when faced with a public affront to their reputation (Nisbett \& Cohen, 1996; see also Anderson, 1994).

\section{Cross-Cultural Study}

A strategy that affords the strengths of both the two-culture and three-culture comparison strategies is the cross-cultural study, in which a wide array of the world's cultures are assessed with the same measure. Whereas the two-culture approach targets universality by looking for similarities in two maximally divergent groups, and the three-culture approach looks for universality by revealing commonalities along two psychological dimensions that vary greatly across cultures, the cross-cultural survey's strength is its sheer coverage of the world's cultures. Statements about universality are greatly strengthened when the findings apply to an approximation of the world's database of cultures. This strategy has been pursued in a number of high-profile research projects (e.g., Buss, 1989; Diener et al., 1995; Hofstede, 1980; Russell, 1991; Schwartz, 1992). A compelling case for universality can be made when a phenomenon is clearly identifiable in a large and diverse array of cultures.

A prototypic example of the cross-cultural study is Daly and Wilson's (1988) investigation into sex differences in homicide. They reviewed evidence from 35 samples in 19 different countries that covered the gamut from contemporary industrialized countries, to hunting and gathering cultures, to 13th-century England. In each sample, men were found to engage in same-sex homicides far more than were women. The breadth of the coverage of their samples renders the evidence for some universality in sex differences in homicide to be rather unassailable, although there is room for debate regarding what particular underlying mechanisms are responsible for the universality (e.g., Eagly \& Wood, 1999).

The cross-cultural study has the greatest potential for making compelling cases about universals. However, there are a number of challenges inherent in this strategy that can work against its effectiveness. Because it is, by nature, an especially costly and effort-intensive strategy, researchers inevitably are drawn to take some shortcuts in its application. For example, the data that tends to be most accessible to psychologists is that from student samples from universities in industrialized cultures. It is quite possible that any identified similarities across such samples would reflect the similar cultural experiences that people in these samples have had rather than revealing broader underlying universals. A more compelling argument for universality would require the inclusion of samples that fall outside of these accessible ones, for example, a dataset that includes nonstudent samples and samples from subsistence societies (for some exemplars of this approach, see Atran, 1998; Berlin \& Kay, 1969; D. Brown, 1991; Fiske, 1991; Henrich et al., in press; Medin \& Atran, 1999; Russell, 1991; Segall et al., 1963). The Human Relations Area Files is a useful tool for gaining access to data from subsistence societies, although one is restricted to looking at the kinds of data that were collected by the original ethnographers. Another way to reduce the difficulty of conducting experiments in a diverse array of cultural contexts is by conducting meta-analyses on studies that have been conducted independently around the world (e.g., see Bond \& Smith's, 1996, meta-analysis of conformity studies with the Asch paradigm).

A second challenge for the cross-cultural study is the trade-off between the amount of experimental rigor that can be applied in a given study and the number of cultures that are included. It is challenging and costly, for example, to run a laboratory study in many different cultures at once and maintain a high degree of experimental control and faithfulness to the local cultural meanings of the variables and experimental procedures. Not surprisingly, the vast majority of psychological studies that target a large number of cultures do so by means of brief questionnaire measures. There are many methodological challenges to comparing cultures, and cross-cultural comparisons of mean responses to subjective Likert scales is a method that is especially prone to methodological artifacts. Without proper experimental controls, such comparisons suffer from moderacy response biases (e.g., Chen, Lee, \& Stevenson, 1995), acquiescent response styles (e.g., Choi \& Choi, 2002), deprivation effects (Peng et al., 1997), and reference-group effects (Heine, Lehman, Peng, \& Greenholtz, 2002). Because of these shortcomings that are inherent in cultural comparisons of Likert scale measures, which are used in so many applications of the cross-cultural survey, this method for exploring universals has rarely been used to its full potential. The crosscultural survey is a powerful tool when used in conjunction with experimental methods that are not contaminated by these methodological shortcomings (see Heine et al., 2002, for a review).

A third challenge facing the cross-cultural study method is to broaden the scope of psychological variables under investigation sufficiently so that many culture-specific conceptions of the variable are not missed. This is especially problematic when a single method is used to assess a variable across cultures; the problem can be alleviated somewhat by multimethod measurement. In either case, however, a narrow conceptualization of a psychological variable can hinder the discovery of universals. With sufficient expansion of the construct to include the diversity of ways in which it is manifested across cultures, genuine universals as well as culture-specific patterns can be identified with greater confidence. For example, subjective well-being and happiness have been fruitfully investigated, and some potentially universal predictors of subjective well being, as well as cultural differences in these predictors, have been identified across cultures (e.g., Diener et al., 1995; Oishi, Diener, Lucas, \& Suh, 1999). Nevertheless, it is conceivable that without adequate examination of a construct's applicability in different cultures, other cultural manifestations of what psychologists consider happiness may be missed, for example spirituality, a sense of connection or union with the natural world, or a sense of living a meaningful yet difficult life.

\section{Section Summary and Conclusions}

Psychologists need not canvass all the world's myriad cultures in search of empirically grounded psychological universals. Cross- 
cultural comparisons, designed with precision and based on the theoretically relevant selection of cultural samples, can yield profound insights into universals. We listed several relatively simple and cost-effective research strategies that can be used to test the degree of generality of a psychological process or phenomenon.

Although we focused on cross-cultural comparisons as the indispensable and definitional tool for establishing the degree of universality of psychological phenomena, we note briefly that several non-cross-cultural research strategies are also available to make a case for universality. These may include cross-species comparisons, such as those identifying the widespread nature of kin selection mechanisms across species (e.g., Hamilton, 1963); studies tracking psychological tendencies such as female sexual attraction or male aggressiveness as a function of biochemical or hormonal fluctuations (e.g., Gangestad, 2004); studies highlighting the neural bases of psychological structures, such as numerical reasoning, drawing on neuroimaging techniques, or examining patients with selective brain injuries (Dehaene, 1997); and infant studies establishing the early emergence of psychological expectancies in infants, such as intuitions regarding physical causation (e.g., Spelke, Phillips, \& Woodward, 1995). However encouraging these approaches are for exploring universality, by themselves they are inadequate for establishing the cross-cultural generality of psychological phenomena. Cultural experience can exert its effects from early infancy, perhaps even in the womb, as is the case for discriminating speech sounds (Mehler et al., 1988; Polka \& Werker, 1994), and throughout adulthood. Furthermore, it is probable that cognitive primitives-regardless of whether they are shared with other species-would be elaborated, added to, and possibly modified by cultural experience. Also, many innate tendencies undergo maturational development and may not emerge at all until later when the child's mind is already fully immersed in and dependent on a cultural environment. Finally, to the extent that sociocultural practices diverge, so will the psychological structures (e.g., Carey, 2004; Cole, 1996; Vygotsky, 1978), often leading to neural specialization of culturally acquired abilities such as reading (Polk et al., 2002). For these reasons, it is critical to combine evidence from these approaches with cross-cultural data that speaks directly to the degree and nature of cross-cultural generality. Cross-cultural comparisons are of central importance in the quest for psychological universals, a matter to which we turn next.

\section{Why Study Psychological Universals?}

The eye cannot see its own lashes—Chinese proverb

We take as our starting point that psychology as a science would be on firmer ground with the discovery and description of empirically tested psychological universals and near-universals ${ }^{3}$ that are genuinely shared by most or all human beings across cultures. Our task, then, is to articulate a conceptual framework that can facilitate research to achieve this goal. We anticipate that most psychologists would agree that, at some level, cultural contexts are implicated in psychological processes. Similarly, we expect that most psychologists would agree that, at some level, members of the human species share universal conceptual and motivational primitives-psychological building blocks, without which cultures and cultural learning would be impossible - that interact with cultural contexts in important ways. Hence, understandings of cultural diversity and universals are viewed as integral to much psychological reasoning. However, the challenge in considering universals within a context of cultural diversity is to target an appropriate level of analysis to make sense of them. At too abstract a level, universals are too diffuse to be of significant empirical import (Geertz, 1973). At too concrete a level, however, it is unlikely that universals will be identified. The key is to articulate the optimal level of abstraction that renders potential universals useful in research, general enough to occur, yet tangible enough to have psychological authenticity.

Psychology's narrow empirical base is an obvious and daunting obstacle to the discovery of genuine psychological universals. Indeed, to the extent that a phenomenon has been identified, say, only in middle-class suburban Chicago, that does not inform whether that phenomenon is similarly present but undocumented elsewhere, present in a different form, or largely absent elsewhere. Perhaps the most important rationale for cross-cultural research, then, is that systematic empirical observation is an essential part of disentangling the culture specific from the universal. Because the forms and practices of one's own culture seem so natural and obvious, it is easy to presume that the psychological processes that we are observing reflect psychological universals, readily spotted in San Francisco, Stockholm, or Sydney. Why, then, bother going to conduct comparable studies in Jordan, Japan, or the remote corners of Java? We argue that this restricted database has led psychologists to inherit a sense of culture blindness, because of which they are prone to conflate psychological universals with their culture-specific manifestations. The problem with such conflations is that they greatly complicate efforts to articulate what particular psychological phenomena have evolved to serve what particular functions.

Consider, for example, the debate over the universality of marriage from the anthropological literature (e.g., Goody, 1977; LeviStrauss, 1969). If defined as a form of institutionalized arrangement for men and women to form a long-term mating relationship that facilitates the conception and caring of offspring, then marriage is universal, as in all cultures there are such relationships that are recognized and privileged (D. Brown, 1991). However, at the level of particular cultural instantiations, we see a wide variety of marriages around the world (e.g., arranged monogamy, voluntary serial monogamy, polygyny, fraternal polyandry, endogamy, and exogamy). If we are interested in articulating the evolutionary origins of marriage, it is crucial that we are targeting the appropriate level of analysis. An evolutionary account that conflates, say, serial monogamy with the more abstract practice of marriage would not be very persuasive given that exclusively monogamous relations are not common in many cultures. In contrast, an evolutionary account for the origins of marriage (i.e., a long-term mating alliance to conceive and care for offspring), given its universal

\footnotetext{
${ }^{3}$ Following the guidelines of D. Brown (1991), we do not make a theoretical distinction between universals (something that exists in all cultures) and near-universals (something that exists in virtually all cultures). Nonexistence is always difficult to prove conclusively, and the failure to identify a process in only one culture, but not in the rest, may occasionally be due to an oversight. To the extent that something appears to be a near-universal, we think it is best to tentatively consider it a universal, unless a more compelling case for nonuniversality can be marshaled.
} 
presence in societies, would be on much firmer ground. However tempting it might be to endeavor to understand the evolutionary origins of marital relations by considering the specific instantiations of them readily available in our culture, one does so at the risk of conflating the particular with the universal. Unless our analyses consider the other specific instantiations of the practice, we cannot determine whether our hypothesis is limited to the concrete, particular level or can address the more encompassing abstract, universal level.

For a psychological example, consider the question of whether a need for positive self-regard is a psychological universal. The idea that people are motivated to seek and maintain a positive self-view is a foundational assumption of many theories in psychology (e.g., Allport, 1955; W. James, 1950/1890; Taylor \& Brown, 1988), and thus, the question of whether a need for positive self-regard is universal is an important one. A perusal of the evidence for motivations for positive self-regard across cultures, however, underscores the importance of being explicit about the level of abstraction that one is considering. One way to consider the question of whether people are motivated to have positive self-regard is to conceive of positive self-regard as selfenhancement. Self-enhancement is operationalized in most empirical studies as tendencies to dwell on and elaborate positive information about the self relative to information about one's weaknesses (e.g., Heine, 2005b; Taylor \& Brown, 1988).

At this level of abstraction there is a great deal of cultural variability in motivations for positive self-regard. Cross-cultural comparisons of East Asians and Westerners reveal consistent and pronounced differences in self-enhancement motivations in dispositional measures of positive self-views, measures of self-serving biases, and reactions to success and failure feedback (Heine et al., 1999). A recent meta-analysis of published studies comparing self-enhancement motivations between East Asians living in East Asia and Westerners found significant cultural differences that emerged consistently with an average effect size of $d=.85$ (Heine \& Hamamura, 2005). Furthermore, whereas studies of selfenhancing biases reveal consistent and pronounced evidence for self-enhancement among Westerners (average $d=.86$ ), overall there is scant evidence for self-enhancement among East Asians living in East Asia (average $d=-.02$ ). This lack of selfenhancement among East Asians does not appear to be due to experimental artifacts (for reviews of debates about these artifacts see Heine, 2003, 2005b; Heine et al., 1999; but for a dissenting view see J. D. Brown \& Kobayashi, 2002). In contrast to the pursuit of self-esteem and a reliance on self-enhancing motivations, East Asians appear to be more concerned with securing face and relying on self-improving motivations (Heine, 2005; Heine et al., 1999). Self-enhancing motivations appear to be far weaker, if not largely absent, among people participating in East Asian contexts.

How might we consider the evolutionary origins of motivations underlying a need for positive self-regard? That tendencies to possess, exaggerate, and make compensatory efforts to maintain positive self-views appear so pervasive and strong within Western samples has led some researchers to propose that this motivation, operationalized as self-enhancement, has been selected for in the ancestral environment. A variety of different accounts have been proposed for how the self-enhancement motive might have emerged as an adaptation. For example, Barkow (1989) proposed that self-esteem was selected to serve as a gauge of subtle changes of the individual's status within dominance hierarchies. Leary and colleagues (Leary, Tambor, Terdal, \& Downs, 1995) argued that self-esteem is an adaptation that functions as an indicator to detect when our social relationships with others are vulnerable. Terror management theory (Pyszczynski, Greenberg, \& Solomon, 2004) maintains that self-esteem emerged as an adaptation that serves to stave off the debilitating existential anxieties that come from fears of mortality. These divergent theories share a common theme: A motivation as powerful and pervasive as self-enhancement must serve to increase fitness, especially given the costs that individuals must sometimes bear for holding these motivations (e.g., Baumeister, Smart, \& Boden, 1996; Paulhus, 1998).

If a theory proposes that self-enhancement has evolved to solve some kind of problem in the ancestral environment, such as status, belongingness, or quelling existential anxieties, then we should see evidence for this motivation in all cultures or at least in all cultures in which concerns with status, belongingness, and existential despair are as evident as they are in the West. As noted, the pronounced lack of evidence for self-enhancing motivations among East Asians suggests that such evolutionary accounts are problematic. If self-enhancement serves the function of maintaining status, belongingness, or quelling existential fears, then why in cultures such as East Asia, in which concerns with status and belongingness are arguably stronger than they are in the West (e.g., Heine, 2001) and existential fears seem to be at least as strong (Heine, Harihara, \& Niiya, 2002), do we see much less evidence of selfenhancement? An evolutionary account of the origins of the selfenhancement motivation needs to be able to address why the motivation appears so much stronger in Western cultures than in East Asia.

A compelling evolutionary account of the origins of a need for positive self-regard, then, would need to consider the adaptive value of such motivations at a level of abstraction at which universality is evident. Positive self-regard can also be considered in terms of being a good self, that is, striving to be the kind of person viewed as appropriate, good, and significant in one's culture (e.g., Crocker \& Park, 2004; D’Andrade, 1984; Heine et al., 1999; Kluckhohn, 1962). Heine and colleagues have argued that motivations for self-enhancement and self-esteem are means to the end of becoming a good self in the West, whereas motivations for self-improvement and face are different means to the same end for East Asians (Heine, 2003, 2005a; Heine et al., 1999). At this level of abstraction, a need for positive self-regard can be a plausible candidate for a psychological universal, and we propose that the most compelling evolutionary accounts for this motivation will be targeted at this level (see Heine, Proulx, \& Vohs, 2005).

Naturally selected psychological processes do not preclude the possibility that such adaptations are expressed in altered forms in different populations (D. Cohen, 2001; Kenrick, 2001; Kenrick et al., 2003). Given that human brains evolved to function in social groups and be responsive to the workings of other minds (e.g., Dunbar, 1992; Tomasello et al., 1993), adaptations such as cooperative behaviors or aggressiveness in males can be best conceptualized as contingent rules that are sensitive to ecological variation (e.g., if neighbor cooperates, then cooperate in return; Kenrick et al., 2003). Variation in the social geometry (e.g., proximity and frequency of encounters with cooperators or competitors; e.g., Vandello, 2004) or variation in demographic imperatives (e.g., the 
distribution of hawks vs. doves in the neighborhood) as well as variation in subsistence niches (herding of animals vs. cooperative agriculture) enable, modify, amplify, and suppress evolved psychological tendencies, resulting in sociocultural diversity in behavior across the world (D. Cohen, 2001). Here, again, the proper level of abstraction is of utmost importance. To the extent that psychologists focus on the wrong level of abstraction, evolutionary explanations will likely lead to theoretical blind alleys.

Cultural psychology is concerned with disentangling the culture-specific level of psychological processes from the processes that are common to all. The challenge of this endeavor is that we rarely encounter psychological processes at the more abstract, universal level directly. They appear to us in culturally instantiated forms. In some cases, the instantiations are not so diverse that the universal processes are clearly discernable (e.g., preferences for sweet and fatty foods, Rozin, 1976; sex differences in violence, Daly \& Wilson, 1988). In others, however, the instantiations are varied enough to distract us from attending to the underlying universals that are hidden from view (e.g., Heine et al., 1999; Markus \& Kitayama, 1991; Nisbett et al., 2001; Shweder et al., 1997). It is only by considering cultural diversity that we can identify where we might be conflating the particular with the universal.

A critical step, then, is to distinguish the culturally instantiated level from the universal underlying level for successfully considering both cultural diversity and universality of psychological phenomena. However, we recognize that discussions about which levels of abstraction are most appropriate tend to be rather abstract, often muddled, and rarely productive, as in many cases there is little agreement with respect to the bases on which the abstractions are grounded. Theoretical confusion is likely to emerge from differing but often unarticulated assumptions of what level of a universal exists across cultures. Research on the universality of psychological processes would be more productive if conceptual frameworks were available to anchor findings and inform debates about levels of universals. Next, we propose such a framework of distinctions regarding cultural differences and universals.

\section{A Hierarchy of Psychological Universals}

We propose three levels of universals and one case of nonuniversal that can be observed cross-culturally. This model rests on a powerful analogy of the mind as a toolbox (Cole, 1996; Piaget, 1952; Resnick, 1994; Stich, 1990; Vygotsky, 1978). Psychological processes, including cognitive structures, emotions, and motivations, can be thought of as tools for thought and behavior. Just as the handyman's specialized toolbox is used to construct, repair, add, and transform, the mental toolbox is accessed to solve the myriad problems of everyday life. In a world joined together by nails, a hammer is a more useful tool than a wrench. In a world held together by nuts and bolts, a wrench is a more useful tool than a hammer. To the extent that the worlds in which people inhabit are different, or are believed to be so, divergent affordances emerge that elicit the use of different tools. Just as hammers might be considered to be more useful tools than wrenches for construction in some contexts, rules might be considered to be more useful tools than exemplars for decision making in some contexts.

This perspective leads us to ask three questions about the comparability of cognitive tools across cultures. First, are the tools in the cognitive toolboxes the same or different across cultures?
Second, even if the tools are the same or nearly the same, are different tools used in the same situations? In other words, do people rely on the same tools to solve a given problem? Third, even if the tools are the same, and the same tools are used to solve a given problem, is the tool accessed with the same facility or frequency? The answers to these three questions suggest four degrees of universality (see Table 1): nonuniversals (different tools), existential universals (same tool but differential functions), functional universals (same tool and same function or use but differential accessibilities), and accessibility universals (same tool, use, and degree of accessibility). Figure 1 charts the decision process of identifying these four levels of psychological universals. We review these four levels below in order from strongest to weakest claims of universality. ${ }^{4}$

\section{Accessibility Universals Versus Cultural Variation}

An accessibility universal (a) is, in principle, cognitively available to most people in most cultures (it is an existential universal); (b) has the same use across cultures (it is also a functional universal); and (c) is accessible to the same degree across cultures. Whereas existential universals have the lowest threshold for universality, and functional universals have a moderate threshold for universality, accessibility universals demand stringent evidence. Conversely, systematic accessibility differences, measured in terms of different effect sizes, undermine claims of accessibility universality.

It seems that many psychological processes are implicitly assumed to be accessibility universals. For many of the processes investigated by psychologists, there is no discussion regarding whether the studies would yield the same findings were they to be conducted with other samples. This absence of discussion on possible variability would often seem to suggest that the process under investigation is assumed to be an accessibility universal.

Examples of accessibility universals. We are unaware of any systematic studies that have explicitly attempted to demonstrate accessibility universals. However, there are some psychological processes for which it would be reasonable to expect little or no systematic cultural variation. One such process is an analog number sense, or quantity estimation. This cognitive ability assesses quantity approximately but, unlike counting, is limited in accuracy. It does not require culturally invented counting systems, appears in early infancy, and is shared by other nonlinguistic higher primates (e.g., Dehaene, 1997). Recent evidence suggests that analog quantity estimation operates in an identical way in preliterate cultures without a counting system beyond "one, two, many," as reflected in the particular pattern of the error rates (Gordon, 2004). Another is the mere exposure effect, or the tendency to experience increased positive affect toward familiar objects relative to unfamil-

\footnotetext{
${ }^{4}$ These are not meant to be different kinds of universals in a metaphysical sense. These levels of universals are continuous, interpenetrating classes. This taxonomy serves as a useful heuristic to guide and synthesize research and provide a common framework for effective communication among researchers. It is an open question whether these universals have differing origins, that is, whether they can be meaningfully traced to different cultural learning mechanisms. In discussions of the universality of a psychological trait or phenomenon, however, it is crucial to be clear as to which level of universal one is referring to.
} 
Table 1

Levels of Psychological Universals in a Hierarchical Taxonomy: Psychological Commonalities Across Cultures

\begin{tabular}{cccll}
\hline Existence & Use & Accessibility & $\begin{array}{l}\text { Required } \\
\text { evidence }\end{array}$ & $\begin{array}{l}\text { Resultant } \\
\text { universal }\end{array}$ \\
\hline Yes & Yes & Yes & Strong & $\begin{array}{l}\text { Accessibility } \\
\text { Yes }\end{array}$ \\
Yes & No & $\begin{array}{l}\text { Moderate } \\
\text { Functional }\end{array}$ \\
No & No & No & Weak & $\begin{array}{l}\text { Existential } \\
\text { Nonuniversal }\end{array}$ \\
\hline
\end{tabular}

iar ones (Zajonc, 1968). This robust affective phenomenon can emerge without any conscious awareness, is impervious to reasoning processes (Winkielman, Zajonc, \& Schwarz, 1997), and is evident across species (e.g., Zajonc, Wilson, \& Rajecki, 1975). For example, human faces that are more similar to the prototypes in their respective cultures, and thus are more familiar, have been found to be viewed as more attractive, and this effect emerges across cultural contexts (e.g., Rhodes et al., 2005). Another is social facilitation (Zajonc, 1965), or the finding that the presence of others can facilitate performance of a dominant (well-learned) behavior and inhibit performance of a nondominant (poorly learned) behavior. This effect is mediated by physiological arousal and occurs widely in the animal kingdom (Zajonc, 1968). Because there is little relevant research that explicitly tests for accessibility universals, identification of the kinds of psychological processes that do not vary systematically across cultures remains speculative. In the absence of systematic cross-cultural data, those processes that would appear to be the best candidates for the label of accessibility universals are those that are identified across species or that appear to operate independently of content and context.

Example of a failure to meet the threshold of accessibility universals. Psychological effects that are assumed to be accessibility universals often turn out to be susceptible to accessibility variations upon closer inspection. Consider, for example, an experiment on category learning comparing the relative accessibilities of exemplar-based versus rule-based categorization among European American, Asian American, and East Asian (Chinese and Korean) undergraduates (Norenzayan, Smith, Kim, \& Nisbett, 2002). Given arguments by historians and philosophers about the differences in Western and Chinese philosophical traditions emphasizing analytic and holistic modes of thought respectively (Lloyd, 1990; Nakamura, 1964/1985), cultural differences were expected in rule-based category learning, especially when rule use conflicted with exemplar use. Participants learned how to catego-

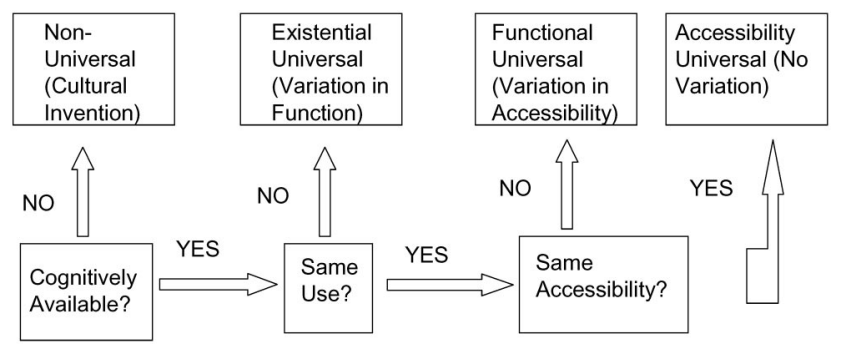

Figure 1. Decision flowchart distinguishing the four levels of psychological universals. rize cartoon animals as being either from Venus or from Saturn (Allen \& Brooks, 1991) by applying a complex, explicit, additive rule. When the rule and the exemplars were in conflict; that is, rule application and similarity to past exemplars led to contradictory inferences regarding category membership, Allan \& Brooks (1991; see also Smith, Patalano, \& Jonides, 1998) found evidence of exemplar interference in rule application, that is, judgments were affected by similarity to exemplars despite instructions to solely follow the rule.

In the Norenzayan, Smith, et al. (2002) study, all three groups showed exemplar interference, indicating that this effect can be generalized across these three cultural groups, a potential functional universal (see Figure 2). However, the size of the effect was different across cultures: East Asians made twice as many classification errors as either European Americans or Asian Americans, indicating that this effect is differentially accessible across cultures. Thus, exemplar interference in category learning is not an accessibility universal. Under identical learning conditions (e.g., learning of novel categories having few members and weak or no prototype structure), East Asian rule-based category learning was twice as likely to be sensitive to exemplars.

\section{Functional Universals Versus Cultural Variation}

When a psychological process shows cultural variability in accessibility, then the next step is to examine whether it is a functional universal. A functional universal (a) is, in principle, cognitively available to people in all cultures; (b) has functionally the same use across cultures; and (c) can vary across cultures in the extent to which it is accessible.

Example of a functional universal. Fiske (1991) reviewed the forms of human relations around the world and proposed that all human relations are composed of four separate relational elements:

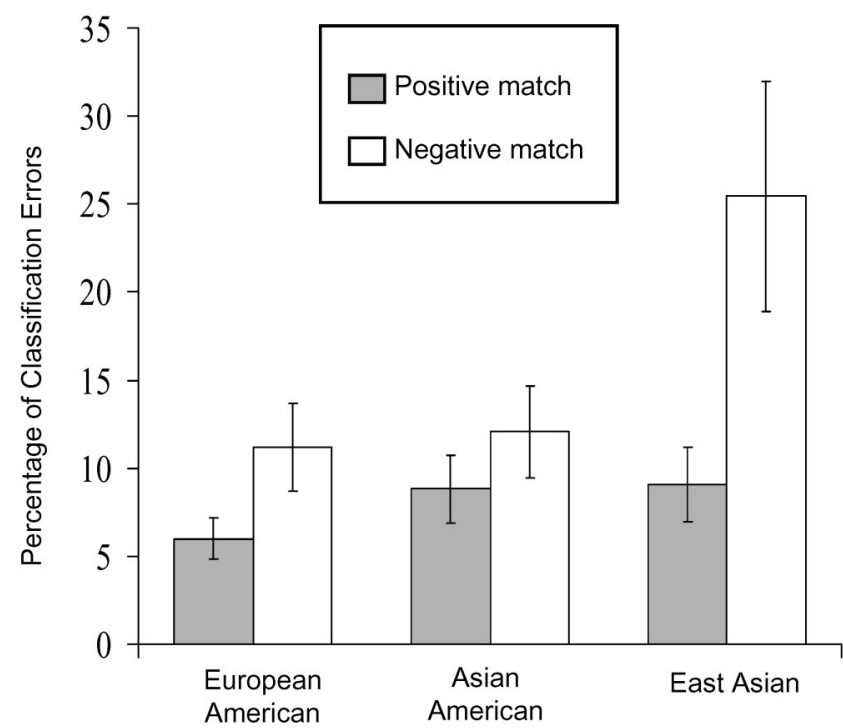

Figure 2. Accessibility difference in category learning. From "Cultural preferences for formal versus intuitive reasoning" by A. Norenzayan, E. E. Smith, B. Kim, and R. E. Nisbett, 2002, Cognitive Science, 26, p. 662. Copyright 2002 by the Cognitive Science Society. Reprinted with permission. 
authority ranking, communal sharing, equality matching, and market pricing. Fiske reviewed a considerable body of evidence gleaned largely from various ethnographic accounts and found strong support that these four relational models are evident in all cultures in which they have been explored; that is, they represent existential universals. Furthermore, Fiske was able to delineate the ways in which the different relational models serve the same basic functions within all contexts and cultures to which they are applied. Hence, they are also proposed to be functional universals. However, Fiske also identifies pronounced cultural variation in the presence of these different relational models across cultures. For example, there is far more evidence of market pricing relations within American culture than within the Moose of Burkina Faso, and likewise, there is more communal sharing among the Moose than among Americans. This cultural variation suggests that relational models are not accessibility universals. The different relational models vary in their accessibility across cultures. The four relational models thus represent functional but not accessibility universals. Some other candidates for functional (but not accessibility) universals include attachment styles (e.g., Grossmann et al., 1995; Miyake, 1993), the similarity-attraction effect (e.g., Heine \& Renshaw, 2002), internal attributions of causality (Norenzayan $\&$ Nisbett, 2002), and the role of negative affect in depression (e.g., Ryder, 2004).

Example of a failure to meet the threshold of functional universals. Other psychological phenomena, presumed to be functional universals, fail to show such cross-cultural similarity. Heine et al. (2001, Study 2) provide an example of a cultural difference in self-enhancing and self-critical motivations that undermines claims that these motivations are functional universals. American and Japanese participants were presented with a creativity task in which they either succeeded or failed in private. Subsequently they were given the opportunity to work on two tasks after the experiment was ostensibly interrupted because of a computer malfunction. One of the tasks was almost identical to the original task; the other task was unrelated to the former. Researchers then covertly measured the length of time that each participant spontaneously worked on the two tasks while waiting for the experimenter to return. Figure 3 reveals that American participants, replicating previous research, persisted longer after success than failure on the original task and were more likely to pursue the novel task when they had failed. In stark contrast, Japanese participants showed the reverse pattern, persisting longer after failure than success on the original task and being more likely to try the novel task if they had succeeded. Based on this and other evidence, Heine et al. argued that Americans approach tasks with a self-enhancing orientation in which they desire to do well. If they fail on a particular task, they can increase their likelihood of succeeding in the future by trying something different. In contrast, Japanese approach tasks with a self-improving orientation in which they desire to eliminate shortcomings. If they fail on a particular task, they can reduce this newly found shortcoming by continuing to persist at it.

This finding reflects a dissociation across cultures (American and Japanese) in a psychological variable (persistence on a task). Variation in achievement outcomes (failure vs. success) led to qualitatively distinct psychological tendencies (self-improvement vs. self-enhancement), even though both cultural groups were motivated to do well. Self-enhancing and self-improving motivations are not universals at the functional level, although they likely

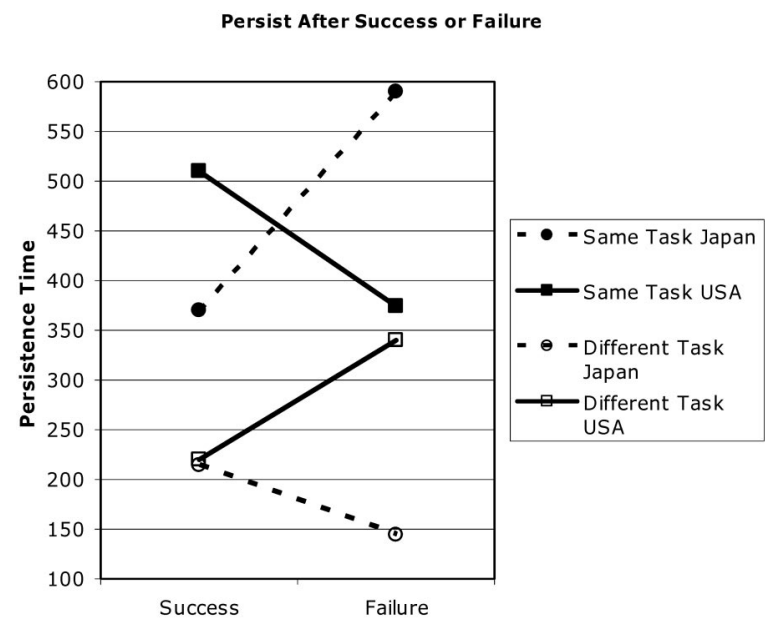

Figure 3. Functional difference in self-enhancing motivations. Persistence time is measured in seconds. From "Divergent consequences of success and failure in Japan and North America: An investigation of self-improving motivations and malleable selves" by S. J. Heine et al., 2001, Journal of Personality and Social Psychology, 81, p. 605. Copyright 2001 by the American Psychological Association. Reprinted with permission.

are existential universals in that these motivations are cognitively available in principle across cultures (Heine et al., 1999).

To summarize, a psychological phenomenon is a functional universal if the shape of the relationship between the variables is the same, even if the strength of the pattern differs across cultures. Conversely, a phenomenon fails the test of a functional universal if qualitatively distinct patterns emerge in different cultures, as in the case of achievement motivation after success or failure. Note, however, that variation in function reflects not the presence or absence of a strategy in the psychological repertoire but the relative dominance of alternative strategies that exist in principle across cultures. In such cases, the next step would be to consider whether these psychological tendencies are indeed existential universals, that is, whether they indeed exist in principle across cultures, even if their use differs markedly.

\section{Existential Universals Versus Nonuniversals}

A psychological tendency is an existential universal if it is in principle cognitively available to normal adults in all cultures, even though the cultures may differ markedly in the ways or frequency with which the process is utilized in everyday life. Existential universals require a very minimal standard of evidence-they refer to psychological strategies that are cognitively latent, even if they are rarely accessed and deployed in practice. Existential universals presume that adult, non-brain-damaged human beings everywhere are capable of accessing and utilizing the same strategies, even if the conditions under which a given strategy is activated may vary dramatically and if the frequency and degree of strength with which a strategy is accessed may vary as well.

Example of an existential universal. An illustration of a cognitive process that reflects variability in function but appears to be an existential universal is a study in which East Asian (Chinese 
and Korean), Asian American, and European American participants judged the similarity of various target objects to one of two categories (Norenzayan, Smith, Kim, \& Nisbett, 2002, Study 2). For example, participants viewed two categories of flowers, with four different flowers in each. Beneath the two categories was a novel flower (the target object). The two categories were constructed so that the use of family resemblance strategy and a rule strategy led to contradictory responses (Kemler-Nelson, 1984). The objects in one category had a strong family resemblance to one another and to the target object without any one feature being necessary to the category. The objects in the opposing category were all definable by a simple deterministic rule (e.g., short stem), without possessing any strong family resemblance structure. To the extent that there are cultural differences in cognitive processes, Western judgments would be rule based (an analytic strategy), whereas East Asian judgments would be family resemblance based (a holistic strategy). The results (see Figure 4, Panel A) indicated that East Asian similarity judgments were indeed primarily driven by family resemblance, whereas European American similarity judgments were primarily driven by the deterministic rule. Asian American judgments were intermediate.

What can we conclude from this study? First, the use of a family resemblance strategy or a rule strategy in judgments of similarity was not cross-culturally uniform. Qualitatively distinct cognitive strategies were recruited to solve a problem under identical task conditions. Despite this cultural variation, it is clear that these two competing cognitive strategies are latent responses that could be activated in principle. For example, when the task requirements were modified to emphasize rule application, all three cultural groups picked the rule over family resemblance (see Figure 4, Panel B). This and other similar studies (see Norenzayan, Smith, et al., 2002) indicate that rule strategies and holistic strategies such as family resemblance are likely to be existential universals, even though they are not functional universals, as their use varies across cultures in systematic ways. Some other candidates for existential (but not functional) universals include the effect of talking on reasoning problems (Kim, 2002) and preferences for individual choice (Iyengar \& Lepper, 1999).

Examples of failures to meet the threshold of existential universals (nonuniversals). Most psychological processes that have been investigated appear to meet the standards of existential universals. However, there are a number of processes that might not. Although the nonexistence of a trait in a population of minds is difficult to demonstrate conclusively, there are several suggestive examples that fail this minimal test of existential universals.

One likely candidate for a nonuniversal is certain arithmetic reasoning strategies that emerge among abacus users but are likely to be nonexistent among nonabacus users (K. F. Miller \& Paredes, 1996). The abacus is a manual counting device that is popular in many East Asian cultures. Compared with nonabacus users-for example, American college students-abacus users reason with numbers in ways that reflect the structural features of the abacus calculating system. For example, abacus users make computational errors particular to the abacus, their reasoning speed correlates with the number of computational steps inherent in the abacus system, and even the nature of their cognitive representations of numbers are different, privileging the odd-even distinction (as opposed to number magnitude), which is a central feature of the abacus system but not other counting devices. These findings can
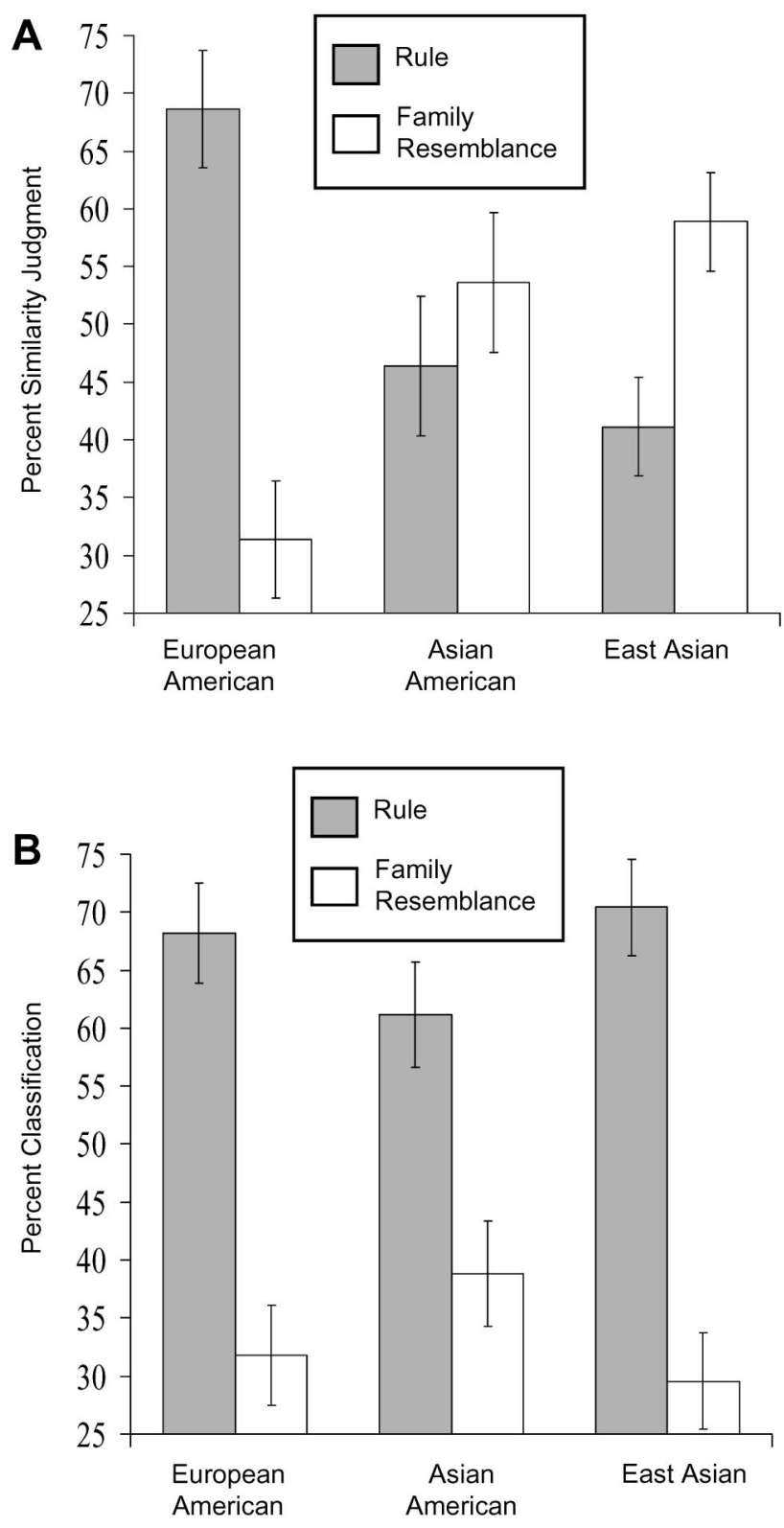

Figure 4. Functional difference in similarity judgments (Panel A) and cross-cultural similarity under instructions that encourage rule application (Panel B). From "Cultural preferences for formal versus intuitive reasoning" by A. Norenzayan, E. E. Smith, B. Kim, and R. E. Nisbett, 2002, Cognitive Science, 26, p. 667. Copyright 2002 by the Cognitive Science Society. Reprinted with permission.

best be explained in terms of cognitive strategies embodied in the abacus as a calculating tool (Vygotsky, 1978). These effects, and presumably the complex computational strategies underlying them, are so peculiar to the abacus that they might be absent from the reasoning of nonabacus users (Hatano \& Osawa, 1983; Stigler, 1984).

Although abacus-based cognitive strategies are perhaps recognizably culture-specific (in that most people are not abacus users), far less obvious is the nature of those cognitive strategies that are 
now widespread across cultures but are in fact rooted in historical inventions that were once culturally bounded. Such a case can be made for the most complex numerical thinking that is observed today across cultures. Numerical thinking appears so early in infants and is so culturally ubiquitous that it is easy to overlook the fact that a host of cultural tools are exploited every time numbers are manipulated - tools that were invented, modified, and built upon by cultural predecessors (Carey, 2004; K. F. Miller \& Paredes, 1996). Undoubtedly, numerical reasoning is rooted in human biology in that infants seem to be naturally endowed with a primitive number sense with an analog representational system of quantity (Dehaene, 1997), natural language quantifiers, and object representation (Carey, 2004). Nevertheless, these core competencies are the cognitive building blocks on which the edifice of human numerical thinking is gradually constructed and transmitted to future generations. Natural numerical competencies available to the human infant are capable of representing one and the difference between one, some, and many. However, the cognitive strategies that make possible the representation of, for example, the number " 31 " or the execution of complex mathematical operations are "bootstrapped" (Carey, 2004). That is, they emerge as a result of the mutual exploitation of primitive representational systems that were initially independent. This bootstrapping is then externalized and culturally transmitted across generations. The inventions of number systems, such as the base-10 structure (as in Indo-Arabic and Chinese numerals), the base-20 (Maya and Aztec), and base-60 (ancient Babylonian) are such cases of cultural bootstrapping. A study that illustrates how the presence or absence of culturally invented number systems can affect numerical reasoning is that of Gordon (2004), who studied counting among the Piraha, an Amazonian tribe with a counting system that does not exceed the number " 3 ." It was found that the Piraha's counting was remarkably poor for items greater than three, despite the fact that their quantity estimation abilities were no different than standard college student populations (see further discussion in the next section). Not only did these cultural tools and associated composite cognitive strategies and representations not exist in principle before the invention and cultural propagation of number systems but the culturally divergent number systems were likely also to have led to important cognitive differences in arithmetic reasoning (K. F. Miller, Smith, Zhu, \& Zhang, 1995).

Similarly, certain statistical reasoning strategies did not exist prior to the emergence of probability theory in 17th-century Europe (Hacking, 1975). In his book The Emergence of Probability, the philosopher Ian Hacking (1975), puzzled at the absence of probabilistic reasoning in the West before Pascal, observes that although games of chance, such as the talus, dice, and deciding by lot, have existed since antiquity, explicit reasoning strategies that made use of the principles underlying such devices simply did not exist prior to the 17 th century:

Probability has two aspects. It is connected with the degree of belief warranted by evidence, and it is connected with the tendency, displayed by some chance devices, to produce stable relative frequencies. Neither of these aspects was self-consciously and deliberately apprehended by any substantial body of thinkers before the time of Pascal. (p. 1)

There is great individual variation regarding the degree of understanding of such reasoning tools, even among highly edu- cated individuals today (Nisbett \& Ross, 1980). Similarly, in the East, Chinese philosophers developed the ancient notion of the Tao as a sophisticated set of conceptual tools to reason about change, contradiction, relativism, and moderation, tools that did not seem to have counterparts in the West (Peng \& Nisbett, 1999), and it is plausible that a host of dialectical reasoning strategies were thus invented and propagated in Chinese culture as a result.

\section{Section Summary and Conclusions}

Universals at the accessibility, functional, and existential levels, as well as nonuniversals, are distinct levels that hierarchically organize the range of identifiable psychological universals. Because of the stringent criteria for their identification, both nonuniversals and accessibility universals are likely to be relatively rare; because of the minimal criteria needed for their occurrence, existential universals are likely to be common. Functional universals fall in between. They inhabit the intermediate bandwidth of the life space, behaviors in a context in which most of the give and take of everyday life occurs. Not surprisingly, much cross-cultural research has targeted what the field presumes to be functional universals. This approach has been fruitful, as the evidence for functional dissociations across cultures is accumulating in processes implicated in reasoning and categorization (Medin \& Atran, 2004; Nisbett, 2003), language development in children (Tardif, 1996), aggression (D. Cohen, Nisbett, Bowdle, \& Schwarz, 1996), motivation and self-regulation (Heine et al., 1999), and the self (Markus \& Kitayama, 1991; Triandis, 1989).

\section{Levels of Universals in Theory Development}

Psychological theories can gain generality, empirical focus, and falsifiability if they are calibrated to account for the observed level of universality in the cross-cultural evidence. Below we illustrate the relevance of levels of universals for two theoretical debates in psychology that implicate universals: the Whorfian or linguistic relativity hypothesis and sexual selection theory in mate preferences.

\section{The Whorfian Hypothesis and Numerical Reasoning}

The notion that cultural experiences influence thought is famously illustrated in the linguistic relativity, or Whorfian, hypothesis (Whorf, 1956), which is the idea that the particular language people speak affects thought. After a period of intellectual stagnation, recently there has been a surge of systematic and compelling studies that have examined and found some degree of support for this hypothesis (e.g., Levinson, 1996; Roberson et al., 2000, 2004), although the precise psychological implications of these studies continue to be debated in the literature (e.g., Levinson, Kita, Haun, \& Rasch, 2002; Li \& Gleitman, 2002).

Whether linguistic differences in counting systems affect numerical reasoning has been one focus of this work. Languages differ markedly in the nature and extent of counting systems that are available to different linguistic communities (K. F. Miller \& Paredes, 1996). Is numerical cognition a psychological universal that is immune to the ways by which languages code numbers, or do linguistic differences lead to cognitive differences in counting? In a recent study, Gordon (2004) examined reasoning among the 
Piraha, an Amazonian group that has a "one, two, ... many" counting system (see also Pica, Lerner, Izard, \& Dehaene, 2004, for a similar study and similar results with the Munduruku of the Amazon). Two main findings emerged. First, counting tasks with varying cognitive demands showed that performance with quantities greater than three were poor. For example, Piraha speakers were shown an array of familiar items (e.g., sticks) and were asked to match these items with the equivalent number of other familiar items (e.g., nuts). Results showed that Piraha speakers had great difficulty matching an array of items if the array contained more than three items.

Second, despite their poor counting performance for numbers that are not available in the Piraha counting system, the participants' estimation errors reflected a constant coefficient of variation; that is, the amount of error increased as a function of the magnitude of the target size. The ratio of this average error to the target size is a constant. Piraha speakers' coefficient of variation was almost identical to that of English speakers. This indicates that Piraha speakers were sensitive to quantity and were trying hard to get the answers correct but were insensitive to exactitude of numbers larger than three.

There is growing consensus in the literature that numerical thinking relies on two independent cognitive strategies: One is a primitive analog number sense that is sensitive to quantity but is limited in accuracy. This cognitive ability is independent of counting practices, can be shown to operate in human infants, and is shared by other nonlinguistic higher primates (e.g., Dehaene, 1997). Second, human infants appear to have a cognitive ability that is sensitive to the exactitude of small numbers, possibly up to about three items. But it is only with the emergence of linguistically coded counting systems and cultural practices of counting that children in some cultures are able to count with exactitude numbers larger than three.

Thus, it appears that the analog number sense is a possible accessibility universal. On the other hand, digital counting beyond three items is likely to be a nonuniversal, a cultural invention that encourages a set of cognitive abilities that simply do not exist without supporting cultural and linguistic practices (but see Gelman \& Gallistel, 2004, for other interpretations of these results). With these distinctions in mind, it becomes clear that past discussions of whether numerical reasoning is universal have targeted the wrong level of universality. One core ability involved in numerical reasoning - analog quantity estimation-seems to pass the highest possible threshold, that of an accessibility universal. Other equally important and pervasive aspects of numerical reasoning — counting beyond three-seem to be the product of the cultural invention of counting systems and are thus nonuniversals. Theories of numerical reasoning can then focus on the mechanisms by which such universals or cultural inventions can emerge in human populations.

\section{Sexual Selection Theory and Gender Differences in Mate Preferences}

As another example of how these distinctions can illuminate debates on the universality of psychological phenomena, consider Buss's (1989) cross-cultural survey of gender differences in mate preferences. Consistent with hypotheses derived from sexual selection theory, Buss predicted and found that in almost all cultures, men valued physical attractiveness and chastity (defined as no sexual experience before marriage) more than did women, whereas women valued status and good financial prospects more than did men. Buss concluded that these preferences are naturally selected psychological universals. However, Buss also found considerable cross-cultural variation in the size of these gender differences. For example, the gender difference in valuing good financial prospects was twice as large in Nigeria as in Belgium. Also, even though in none of the cultures did women value chastity more than men, there was robust cultural variation in whether men preferred chaste women, with no appreciable gender difference in Sweden and a large gender difference in Nigeria. In fact, the overall results indicated that the respondents' culture was a stronger predictor of their mate preferences (for all traits considered) than gender. Eagly and Wood (1999) reanalyzed Buss's data and demonstrated that the size of the gender differences varied systematically as a function of measures of gender inequality in each culture, such that the gender effect increased with more gender inequality. Eagly and Wood concluded that the results are consistent with social structural theories of gender differences.

These explanations are not mutually exclusive and, indeed, can be complementary. That gender effects were found consistently across cultures, despite variation in their size, supports the conclusion that gender differences predicted by sexual selection theory are functional universals. On the other hand, that the size of the effect varies dramatically across cultures, despite the same trend emerging in most cultures, also supports the conclusion that these gender differences fail the test of accessibility universals.

No doubt, the distinctions of universals we are proposing will be fruitfully debated, elaborated, and updated. However, theories can gain clarity and precision if they account for universality and variation at different conceptual levels. Specifying the particular level at which a universal is posited can sharpen theoretical debates like these. Moreover, as evidence accumulates in an area of research, classifying the evidence in terms of these levels of universals can further facilitate communication among researchers and aid in theory refinement.

\section{Conclusions, Implications, and Caveats}

\section{Psychological Universals at the Junction of Evolutionary and Cultural Psychology}

Psychological universals, as fundamental as they are to psychology, have been a neglected topic of empirical analysis for most of the field's history. However, two important recent trends in psychology have been converging toward a new geography in which the reaches and limits of universals can be explored systematically. First, evolutionary psychology has emerged as a new major force within psychology, examining how specific mental modules were naturally selected to solve adaptive problems in the ancestral environment (Barkow et al., 1992; Pinker, 1997). Because the dominant reasoning in evolutionary psychology presupposes a species-specific psychological nature, one standard of evidence by which evolutionary psychological arguments have been evaluated is the extent to which the findings generalize across cultural groups. Toward this end, several lines of research within evolutionary psychology have sought to recruit evidence from samples beyond those of Western university students and from the world 
more broadly (e.g., Buss, 1989, regarding sex differences in mate preferences; Ekman et al., 1969, regarding emotional expressions; Burnstein, Crandall, \& Kitayama, 1994, regarding kin selection and altruism; Daly \& Wilson, 1988, regarding sex differences in homicide). A second, emerging approach in evolutionary psychology is to view naturally selected psychological adaptations as flexible algorithms responsive to local contextual cues that shape and are shaped by population level dynamical processes (e.g., Kenrick et al., 2003; Schaller \& Crandall, 2004). Inherent in this approach is a consideration of the ways in which psychological adaptations express themselves differently in divergent cultural environments. As a result of these dual trends, a number of evolutionary psychology research programs have moved from treating universality as an untested assumption to treating universality and its boundary conditions as being actively investigated hypotheses.

Second, the past two decades have seen growth in the field of cultural psychology. Cultural psychology is grounded in the observation that humans have a dual inheritance, that of biological evolution and transmitted culture. These are relatively independent yet mutually interacting forces that shape human psychology (Richerson \& Boyd, 2004; Sperber, 1996). Thus, human minds develop in and draw from richly structured cultural contexts, and collectively distributed beliefs and practices in turn are invariably shaped by individual psychological processes and their social and material effects. Thus, cultures and psyches make each other up in a mutually reinforcing fashion and can best be understood in terms of each other (Cole, 1996; Fiske et al., 1998; Markus \& Kitayama, 1991; Shweder, 1991; Vygotsky, 1978). Accordingly, cultural psychologists have sought to investigate the influences of cultural environments on the psyche by exploring differences between cultures in core psychological processes. These research programs have revealed that cultural variability seeps much deeper into the very structures of the mind than previously thought, sometimes bypassing the conscious mind altogether (D. Cohen, 1997). Advances in cross-cultural methods and a growing cross-cultural literature has allowed researchers to incorporate cultural variation in their psychological models (Choi, Nisbett, \& Norenzayan, 1999; Medin \& Atran, 2004; J. G. Miller, 1999). Cultural psychologists typically do not assume universals, at least usually not at the level of the phenomenon under investigation, and are actively testing the degree of variability in assumed universals.

It has been the recent growth of evolutionary and cultural psychology that has taken the issue of psychological universals from an implicit assumption to an actively investigated hypothesis. Both fields are actively involved in testing the question of psychological universals; evolutionary psychologists typically seek evidence for universals, and cultural psychologists typically seek evidence for diversity. However, there are encouraging points of convergence in the two fields' complementary approaches of seeking the conditions under which universal mechanisms are expressed in culturally specific ways (Kenrick et al., 2003). These approaches involve considering the evolved constraints on cultural diversity (e.g., Atran \& Norenzayan, 2004; Boyer, 1994; Henrich \& Boyd, 1998; Kameda, Takezawa, \& Hastie, 2003; Norenzayan \& Atran, 2004) and conceptualizing human nature in terms of naturally selected psychological adaptations that are incomplete without culture-specific instantiation and coordination, which are mutually complementary and mutually necessary for psychologi- cal functioning (D. Cohen, 2001; Fiske, 2000; Kameda \& Nakanishi, 2003; Nisbett \& Norenzayan, 2002; Rozin, 2001).

\section{Universality, Cultural Variability, and the Argument for Innateness}

Universality is an important consideration for determining whether psychological phenomena are explainable in terms of innate structures or learned responses. However arguing for universality is distinct from arguing for innateness. In this regard, three important points about explanations for universals are worth considering briefly. At the most abstract level, processes could be universal because they are the result of (a) innate, naturally selected psychological tendencies that emerge everywhere in the same ontogenetic sequence (such as language acquisition, Pinker \& Bloom, 1992), (b) cultural byproducts of naturally selected tendencies (such as religion, e.g., Atran \& Norenzayan, 2004), or (c) independent cultural inventions or cultural diffusions of learned responses that serve a useful purpose everywhere, such as counting systems, calendars, writing, trading, and cognitions and behaviors associated with these inventions, or what Dennett (1995) refers to as "good tricks" (p. 486).

Thus, universality is encouraging but not conclusive evidence for the innateness of a psychological process. An argument for the innateness of a process has to show that the process is unlikely to have achieved universality because of repeated independent inventions or because of widespread cultural propagation of inventions.

On the other hand, could cultural variability reflect the innateness of a psychological process? Perhaps the cultural variability in psychological processes that has been discovered is due not to differential cultural transmission of psychological traits, as has been argued (e.g., Boyd \& Richerson, 1985; Markus \& Kitayama, 1991; Nisbett et al., 2001) but rather to differential genetic transmission that covaries with the samples. After all, much work in behavioral genetics has highlighted how psychological processes have a significant heritable component (e.g., Plomin, Owen, \& McGuffin, 1994; Roy, Neale, \& Kendler, 1995; Turkheimer, 2000). Furthermore, recent research on the Human Diversity Genome project has identified a number of genes that systematically vary across populations (e.g., Cavalli-Sforza \& Cavalli-Sforza, 1995), including genes associated with distinct blood groups (Landsteiner, 1901), lactose intolerance (Flatz, 1987), and resistance to malaria (Allison, 1954). Might there also be systematic population variance in genes that are in some ways linked to psychological phenomena?

If group-level psychological differences are associated with group-level genetic differences, selection pressures must have diverged in different populations. Cavalli-Sforza and CavalliSforza (1995) argue that we should see the greatest differential selection pressures on traits that have the most consistent and powerful consequences on fitness and that occur over long periods of time, such as those related to thermal regulation, pathogen resistance, and diet. However, culturally differential selective pressures for psychological traits were likely not consistent over long periods of time because cultures are constantly in flux. Most large-scale societal changes that separate cultures today, with the possible exception of the agricultural revolution that occurred in some societies 10,000 years ago, have very short time frames that 
preclude the impact of significant culturally differential selective pressures on the gene pool.

It would seem that the best way to empirically address the question of whether variation in genes or in cultural practices underlies cultural variation in psychological processes would be to contrast groups such that race is held constant but culture is varied. Immigrants and their descendants provide practical samples that afford this investigation. Thus far, the data are quite consistent in showing that immigrants and their descendants exhibit psychological processes intermediate to their ancestors who remained in their heritage culture and their compatriots in their host culture, providing evidence for cultural transmission. For example, Asian Americans quite consistently appear intermediate to Asians in Asia and Americans of European descent for a variety of psychological processes (e.g., Kitayama, Markus, Matsumoto, \& Norasakkunkit, 1997; Norenzayan, Smith, et al., 2002), and if anything, they tend to be much closer to the norm for European Americans (Heine \& Hamamura, 2005). Furthermore, the longer people of Asian descent have been in North America, the more closely their psychological tendencies resemble those of North Americans of European descent to the point that third-generation Asian-Canadians are indistinguishable from Canadians of other cultural backgrounds (Heine \& Lehman, 2004; see also McCrae, Yik, Trapnell, Bond, \& Paulhus, 1998). At present we know of no compelling empirical evidence to suggest an innate basis of the cultural differences that have been identified in psychological studies.

\section{Psychological Universals and Managing Cross-Cultural Relations}

Psychological universals are also important to the extent that interventions designed to solve social and psychological problems in other cultures are grounded in certain psychological assumptions about universal human nature. International interventions to combat child abuse in the slums of Brazil, to reduce poverty in the remote villages of Botswana, or to address the needs of the mentally ill in Bolivia are premised on the idea that there is universal agreement as to the meaning and psychological nature of these problems. To the extent that "child," "abuse," "poverty," and "mental illness" are conceptualized differently or function differently, culturally different possibilities for interventions emerge.

It is not new to suggest that there are significant potential costs for judging other cultures from the vantage point of one's own culture. This has been a significant voice from anthropology since Franz Boas and his students (e.g., Benedict, 1934; Boas, 1930; Mead, 1928). However, we propose that such relativism is groundless unless it can be founded on some widely shared psychological tendencies and values. Without systematic cross-cultural investigation, it is difficult to know whether social practices and moral intuitions are rooted in core universal psychology or are the result of projections from particular cultural assumptions of proper personhood and the good and moral life. Thus it is important to place any social interventions into the affairs of other cultures on firm ground that is based on clear knowledge of universals and their boundary conditions as well as the particular prerogatives and psychological preferences of those cultures that may differ considerably from one's own. This is not a call for unbridled cultural relativism but, to echo Shweder (2000, 2002), a call to be slow to judge other cultures. Psychological universals thus have a central role to play in this endeavor, because they possibly provide the only legitimate criteria by which any particular sociocultural practice or belief system may be judged. As Fox (1973, p. 13) has said, "We could not plead against inhuman tyrannies if we did not know what is inhuman."

\section{Summary and Research Directions}

This article outlined a framework to guide the discovery of psychological universals at the proper level of analysis. We sketched a theoretical and methodological map for identifying and explaining universals. The emerging fields of cultural psychology and evolutionary psychology, although initially inspired by divergent concerns and aims, are showing signs of partial convergence toward an interest in the empirical discovery of psychological universals and their limits. In this regard, the study of universals is a key development that can facilitate evolutionary explanations of psychological processes as well as offer a greater understanding of the genuinely shared characteristics of human beings, without which managing cross-cultural relations is fraught with difficulties. Three cross-cultural research strategies that can expand our understanding of psychological universals were discussed. Psychologists need not do exhaustive analysis of countless cultures of the world in search of universals. Relatively simple research strategies are available that, in combination and conjunction with ethnographic, archeological, and archival evidence, can shed light on the psychological building blocks that unite human beings everywhere. Finally, four distinct levels of hierarchically organized universals with varying degrees of claims for universality were outlined. These levels should serve to facilitate and sharpen discussions regarding the universality of psychological processes.

Psychology is at the cusp of expanding its narrow empirical base from middle-class, technologically advanced, primarily Western college-aged samples to humanity at large, with all its cultural diversity. As the field of psychology absorbs the lessons of cultural variability, greater empirical attention to psychological universals, their scope, contours, and the conditions under which they emerge, stand to greatly advance the field.

\section{References}

Abelson, R. P. (1996). Statistics as principled argument. Hillsdale, NJ: Erlbaum.

Alexander, R. D. (1979). Darwinism and human affairs. Seattle: University of Washington Press.

Allen, S. W., \& Brooks, L. R. (1991). Specializing in the operation of an explicit rule. Journal of Experimental Social Psychology, General, 120, 3-19.

Allison, A. C. (1954). The distribution of the sickel-cell trait in East Africa and elsewhere, and its apparent relationship to the incidence of subtertian malaria. Transactions of the Royal Society of Tropical Medicine and Hygiene, 48, 312-318.

Allport, G. W. (1955). Becoming. New Haven, CT: Yale University Press. Anderson, E. (1994). The code of the streets. The Atlantic Monthly, 5, 81-94.

Atran, S. (1998). Folkbiology and the anthropology of science: Cognitive universals and cultural particulars. Behavioral and Brain Sciences, 21 547-569.

Atran, S., Medin, D. L., Lynch, E., Vapnarsky, V., Ucan Ek', \& Sousa, P. (2001). Folkbiology doesn't come from folkpsychology: Evidence from 
Yukatec Maya in cross-cultural perspective. Journal of Cognition and Culture 1, 4-42.

Atran, S., \& Norenzayan, A. (2004). Religion's evolutionary landscape: Counterintuition, commitment, compassion, communion. Behavioral and Brain Sciences, 27, 713-770.

Atran, S., \& Sperber, D. (1991). Learning without teaching. In L. Tolchinsky-Landsmann (Ed.), Culture, schooling and psychological development (pp. 39-55). Norwood, NJ: Ablex.

Avis, J., \& Harris, P. L. (1991). Belief-desire reasoning among Baka children: Evidence for a universal conception of mind. Child Development, 62, 460-467.

Bailenson, J. N., Shum, M., Atran, S., Medin, D. L., \& Coley, J. (2002). A bird's eye view: Biological categorization and reasoning within and across cultures. Cognition, 84, 1-53.

Barkow, J. H. (1989). Darwin, sex, and status: Biosocial approaches to mind and culture. Toronto, Canada: University of Toronto Press.

Barkow, J. H., Cosmides, L., \& Tooby, J. (Eds.). (1992). The adapted mind: Evolutionary psychology and the generation of culture. London: Oxford University Press.

Baumeister, R., Smart, L., \& Boden, J. M. (1996). Relation of threatened egotism to violence and aggression: The dark side of high self-esteem. Psychological Review, 103, 5-33.

Benedict, R. (1934). Patterns of culture. New York: Houghton Mifflin.

Benjamin, L. T. (1988). A history of psychology: Original sources and contemporary research. New York: McGraw-Hill.

Berlin, B. (1992). Ethnobiological classification: Principles of categorization of plants and animals in traditional societies. Princeton, NJ: Princeton University Press.

Berlin, B., \& Kay, P. (1969). Basic color terms: Their universality and evolution. Berkeley: University of California Press.

Berry, J. (1969). On cross-cultural comparability. International Journal of Psychology, 4, 119-128.

Berry, J., Poortinga, Y., \& Pandey, J. (1997). Handbook of cross-cultural psychology: Vol. 1. Theory and method (2nd ed.). Boston: Allyn \& Bacon.

Block, N. (1995). The mind as the software of the brain. In E. E. Smith \& D. N. Osherson (Eds.), Thinking (Vol. 3, 2nd ed., pp. 377-425). Cambridge, MA: MIT Press.

Boas, F. (1930). Anthropology. In Encyclopedia of the Social Sciences (pp. 73-110). New York: McMillan.

Bond, R., \& Smith, P. B. (1996). Culture and conformity: A meta-analysis of studies using Asch's $(1952,1956)$ line judgment task. Psychological Bulletin, 119, 111-137.

Bourdieu, P. (1977). Outline of a theory of practice. Cambridge, England: Cambridge University Press

Boyd, R., \& Richerson, P. (1985). Culture and the evolutionary process. Chicago: University of Chicago Press

Boyd, R., \& Silk, J. B. (2003). How humans evolved (3rd ed.). New York: Norton.

Boyer, P. (1994). Cognitive constraints on cultural representations: Natural ontologies and religious ideas. In L. A. Hirschfeld \& S. A. Gelman (Eds.), Mapping the mind: Domain-specificity in cognition and culture. Cambridge, England: Cambridge University Press.

Brightman, R. (1995). Forget culture: Replacement, transcendence, relaxification. Cultural Anthropology, 10, 509-526.

Brown, D. (1991). Human universals. San Francisco: McGraw-Hill.

Brown, J. D., \& Kobayashi, C. (2002). Self-enhancement in Japan and America. Asian Journal of Social Psychology, 5, 145-168.

Burnstein, E., Crandall, C., \& Kitayama, S. (1994). Some neo-Darwinian decision rules for altruism: Weighing cues for inclusive fitness as a function of the biological importance of the decision. Journal of Personality and Social Psychology, 67, 773-789.

Buss, D. M. (1989). Sex differences in human mate preferences: Evolu- tionary hypotheses tested in 37 cultures. Behavioral and Brain Sciences, $12,1-49$.

Carey, S. (1985). Conceptual change in childhood. Cambridge, MA: Bradford Books.

Carey, S. (2004). Bootstrapping and the origins of concepts. Daedalus, $133,59-68$

Cavalli-Sforza, L. L., \& Cavalli-Sforza, F. (1995). The great human diasporas: The history of diversity and evolution. Reading, MA: Perseus Books.

Chen, C., Lee, S.-Y., \& Stevenson, H. W. (1995). Response style and cross-cultural comparisons of rating scales among East Asian and North American students. Psychological Science, 6, 170-175.

Choi, I., \& Choi, Y. (2002). Culture and self-concept flexibility. Personality and Social Psychology Bulletin, 28, 1508-1517.

Choi, I., \& Nisbett, R. E. (1998). Situational salience and cultural differences in the correspondence bias and in the actor-observer bias. Personality and Social Psychology Bulletin, 24, 949-960.

Choi, I., Nisbett, R. E., \& Norenzayan, A. (1999). Causal attribution across cultures: Variation and universality. Psychological Bulletin, 125, 47-63.

Clifford, J., \& Markus, G. (Eds.). (1986). Writing culture: The poetics and politics of ethnography. Berkeley: University of California Press.

Cohen, A. B., \& Rozin, P. (2001). Religion and the morality of mentality. Journal of Personality and Social Psychology, 81, 697-710.

Cohen, D. (1997). Ifs and thens in cultural psychology. In R. S. Wyer (Ed.), Advances in social cognition (Vol. X, pp. 121-132). Mahwah, NJ Erlbaum.

Cohen, D. (2001). Cultural variation: Considerations and implications. Psychological Bulletin, 127, 451-471.

Cohen, D., Nisbett, R. E., Bowdle, B., \& Schwarz, N. (1996). Insult, aggression, and the Southern culture of honor. Journal of Personality and Social Psychology, 70, 945-960.

Cole, M. (1996). Cultural psychology: A once and future discipline. Cambridge, MA: Belknap Press.

Comrie, B. (1981). Language universals and linguistic typology: Syntax and morphology. Cambridge, MA: Basil Blackwell.

Crocker, J., \& Park, L. E. (2004). The costly pursuit of self-esteem. Psychological Bulletin, 130, 392-414.

Daly, M., \& Wilson, M. (1988). Homicide. New York: Aldine de Gruyter.

D’Andrade, R. (1984). Cultural meaning systems. In R. A. Shweder \& R. A. Levine (Eds.), Culture theory: Essays on mind, self, and emotion (pp. 88-119). Cambridge, England: Cambridge University Press.

Dehaene, S. (1997). The number sense: How the mind creates mathematics. Oxford, England: Oxford University Press.

Dennett, D. C. (1995). Darwin's dangerous idea: Evolution and the meanings of life. New York: Simon \& Schuster.

Diamond, J. (1997). Guns, germs and steel: The fates of human societies. New York: Norton.

Diener, E., Diener, M., \& Diener, C. (1995). Factors predicting the subjective well-being of nations. Journal of Personality and Social Psychology, 69, 851-864.

Dobzhansky, T. (1962). Mankind evolving: The evolution of the species New York: Bantam Books.

Dunbar, R. I. M. (1992). Neocortex size as a constraint on group size in primates. Journal of Human Evolution, 20, 469-493.

Durkheim, E. (1965). The elementary forms of the religious life. New York: Free Press. (Original work published 1915)

Eagly, A. H., \& Wood, W. (1999). The origins of sex differences in human behavior: Evolved dispositions versus social roles. American Psychologist, 54, 408-423.

Edgerton, R. (1971). The individual in cultural adaptation. Los Angeles: University of California Press.

Ekman, P. (1994). Strong evidence for universals in facial expressions: A reply to Russell's mistaken critique. Psychological Bulletin, 115, 268287 
Ekman, P., Sorenson, E. R., \& Friesen, W. V. (1969, April 4). Pan-cultural elements in facial displays of emotions. Science, 164, 86-88.

Elfenbein, H. A., \& Ambady, N. (2002). On the universality and cultural specificity of emotion recognition: A meta-analysis. Psychological Bulletin, 128, 203-235.

Elliot, A. J., Chirkov, V. I., Kim, Y., \& Sheldon, K. M. (2001). A cross-cultural analysis of avoidance (relative to approach) personal goals. Psychological Science, 12, 505-510.

Fiske, A. P. (1991). Structures of social life. New York: Free Press.

Fiske, A. P. (2000). Complementarity theory: Why human social capacities evolved to require cultural complements. Personality and Social Psychology Review, 4, 76-94.

Fiske, A. P., Kitayama, S., Markus, H. R., \& Nisbett, R. E. (1998). The cultural matrix of social psychology. In D. T. Gilbert, S. T. Fiske, \& G. Lindzey (Eds.), Handbook of social psychology (4th ed., pp. 915-981). Boston: McGraw-Hill.

Flatz, G. (1987). Genetics of lactose digestion in humans. Advances in Human Genetics, 16, 1-77.

Flavell, J. H., Zhang, X.-D., Zou, H., Dong, Q., \& Qi, S. (1983). A comparison of the appearance-reality distinction in the People's Republic of China and the United States. Cognitive Psychology, 15, 459-466.

Fox, J. R. (1973). Encounter with anthropology. New York: Harcourt Brace Jovanovich.

Gangestad, S. W. (2004). Women's preferences for male behavioral displays change across the menstrual cycle. Psychological Science, 15, 203-206.

Geertz, C. (1973). The growth of culture and the evolution of mind. In C. Geertz (Ed.), The interpretation of cultures (pp. 55-87). New York: Basic Books.

Gelman, R., \& Gallistel, C. R. (2004, October 15). Language and the origin of numerical concepts. Science, 306, 441-443.

Gergen, K. J. (1973). Social psychology as history. Journal of Personality and Social Psychology, 26, 309-320.

Goodenough, W. H. (1970). Description and comparison in cultural anthropology. Chicago: Aldine.

Goody, J. R. (1977). Production and reproduction: A comparative study of the domestic domain. Cambridge, England: Cambridge University Press.

Gordon, P. (2004, October 15). Numerical cognition without words: Evidence from Amazonia. Science, 306, 496-499.

Grossmann, K., Grossmann, K. E., Spangler, S., Suess, G., \& Unzner, L. (1985). Maternal sensitivity and newborn attachment orientation responses as related to quality of attachment in northern Germany. Monographs of the Society for Research in Child Development, 50(1, Serial No. 209), 233-256

Hacking, I. (1975). The emergence of probability. Cambridge, England: Cambridge University Press.

Hamilton, W. D. (1963). The evolution of altruistic behavior. American Naturalist, 97, 354-356.

Hansen, I. G. (2005). The psychological confluence and divergence of religion and culture and the implications for tolerance. Unpublished manuscript, University of British Columbia.

Hatano, G., \& Osawa, K. (1983). Digit memory of grand experts in abacus-derived mental calculation. Cognition, 5, 47-55.

Heider, E. R., \& Oliver, C. C. (1972). The structure of the color space in naming and memory for two languages. Cognitive Psychology, 3, 337354

Heine, S. J. (2001). Self as cultural product: An examination of East Asian and North American selves. Journal of Personality, 69, 881-906.

Heine, S. J. (2003). Self-enhancement in Japan? A reply to Brown and Kobayashi. Asian Journal of Social Psychology, 6, 75-84.

Heine, S. J. (2005a). Constructing good selves in Japan and North America. In R. M. Sorrentino, D. Cohen, J. M. Olson, \& M. P. Zanna (Eds.), Culture and Social Behavior: The Tenth Ontario Symposium (pp. 115143). Hillsdale, NJ: Erlbaum.
Heine, S. J. (2005b). Where is the evidence for pancultural selfenhancement? A reply to Sedikides, Gaertner, \& Toguchi. Journal of Personality and Social Psychology.

Heine, S. J., \& Hamamura, T. (2005). In search of East Asian selfenhancement. Manuscript submitted for publication.

Heine, S. J., Harihara, M., \& Niiya, Y. (2002). Terror management in Japan. Asian Journal of Social Psychology, 5, 187-196.

Heine, S. J., Kitayama, S., Lehman, D. R., Takata, T., Ide, E., Leung, C., \& Matsumoto, H. (2001). Divergent consequences of success and failure in Japan and North America: An investigation of self-improving motivations and malleable selves. Journal of Personality and Social Psychology, 81, 599-615.

Heine, S. J., \& Lehman, D. R. (2004). Move the body, change the self: Acculturative effects on the self-concept. In M. Schaller \& C. Crandall (Eds.), Psychological Foundations of Culture (pp. 305-331). Mahwah, NJ: Erlbaum.

Heine, S. J., Lehman, D. R., Markus, H. R., \& Kitayama, S. (1999). Is there a universal need for positive self-regard? Psychological Review, 106, $766-794$.

Heine, S. J., Lehman, D. R., Peng, K., \& Greenholtz, J. (2002). What's wrong with cross-cultural comparisons of subjective Likert scales? The reference-group problem. Journal of Personality and Social Psychology, 82, 903-918.

Heine, S. J., Proulx, T., \& Vohs, K. D. (in press). Meaning maintenance: On the coherence of social motivations. Personality and Social Psychology Review. Manuscript submitted for publication.

Heine, S. J., \& Renshaw, K. (2002). Interjudge agreement, selfenhancement, and liking: Cross-cultural divergences. Personality and Social Psychology Bulletin, 28, 442-451.

Henrich, J., \& Boyd, R. (1998). The evolution of conformist transmission and between-group differences. Evolution and Human Behavior, 19, 215-242.

Henrich, J., R., Boyd, R., Bowles, H., Camerer, C., Fehr, E., \& Gintis, H., et al. (in press). "Economic man" in cross-cultural perspective: Ethnography and experiments from 15 small-scale societies. Behavioral and Brain Sciences.

Hirschfeld, L. A., \& Gelman, S. A. (Eds.). (1994). Mapping the mind: Domain-specificity in cognition and culture. Cambridge, England: Cambridge University Press.

Hofstede, G. (1980). Culture's consequences: International differences in work-related values. Beverly Hills, CA: Sage.

Hsee, C., \& Weber, E. U. (1999). Cross-national differences in risk preference and lay predictions. Journal of Behavioral Decision Making, $12,165-179$.

Iyengar, S. S., \& Lepper, M. R. (1999). Rethinking the value of choice: A cultural perspective on intrinsic motivation. Journal of Personality and Social Psychology, 76, 349-366.

James, S. (2002). Agonias: The social and sacred suffering of Azorean immigrants. Culture, Medicine, and Psychiatry, 26, 87-110.

James, W. (1890). The principles of psychology. New York: Dover Publications. (Original work published 1950)

Kameda, T., \& Nakanishi, D. (2003). Does social/cultural learning increase human adaptability? Rogers's question revisited. Evolution and Human Behavior, 24, 242-260.

Kameda, T., Takezawa, M., \& Hastie, R. (2003). The logic of social sharing: An evolutionary game analysis of adaptive norm development. Personality and Social Psychology Review, 7, 2-19.

Kemler-Nelson, D. G. (1984). The effect of intention on what concepts are acquired. Journal of Verbal Learning and Verbal Behavior, 23, 734 759.

Kenrick, D. T. (2001). Evolutionary psychology, cognitive science and dynamical systems: Building an integrative paradigm. Current Directions in Psychological Science, 10, 13-17.

Kenrick, D. T., Li, N. P., \& Butner, J. (2003). Dynamical evolutionary 
psychology: Individual decision-rules and emergent social norms. Psychological Review, 1, 3-28.

Kim, H. (2002). We talk, therefore we think? A cultural analysis of the effect of talking on thinking. Journal of Personality and Social Psychology, 83, 828-842.

Kim, H., \& Markus, H. R. (1999). Deviance or uniqueness, harmony or conformity? A cultural analysis. Journal of Personality and Social Psychology, 77, 785-800.

Kitayama, S., Markus, H. R., \& Kurokawa, M. (2000). Culture, emotion, and well-being: Good feelings in Japan and the United States. Cognition and Emotion, 14, 93-124.

Kitayama, S., Markus, H. R., Matsumoto, H., \& Norasakkunkit, V. (1997). Individual and collective processes in the construction of the self: Self-enhancement in the United States and self-criticism in Japan. Journal of Personality and Social Psychology, 72, 1245-1267.

Kleinman, A. (1982). Neurasthenia and depression: A study of somatization and culture in China. Culture, Medicine, and Psychiatry, 6, 117190.

Klineberg, O. (1954). Social psychology. New York: Holt.

Kluckhohn, C. (1953). Universal categories of culture. In A. L. Kroeber (Ed.), Anthropology Today: An Encyclopedic Inventory (pp. 507-523). Chicago: University of Chicago Press.

Kluckhohn, C. (1962). Culture and behavior. New York: Free Press of Glencoe.

Landsteiner, K. (1901). Uber agglutinationserscheinungen normalen menschlichen [About agglutination effects in normal human blood]. Wiener Klin Wochenschr, 14, 1132-1134.

Leary, M. R., Tambor, E. S., Terdal, S. K., \& Downs, D. L. (1995). Self-esteem as an interpersonal monitor: The sociometer hypothesis. Journal of Personality and Social Psychology, 68, 518-530.

Lee, S. (1995). Reconsidering the status of anorexia nervosa as a culturebound syndrome. Social Science and Medicine, 42, 21-34.

Levinson, S. C. (1996). Language and space. Annual Review of Anthropology, 25, 353-382.

Levinson, S. C., Kita, S., Haun, D. B. M., \& Rasch, B. (2002). Returning the tables: Language affects spatial reasoning. Cognition, 84, 155-188.

Levi-Strauss, C. (1969). The elementary structures of kinship. Boston: Bacon Press.

Li, P., \& Gleitman, L. (2002). Turning the tables: Language and spatial reasoning. Cognition, 83, 265-294.

Liebowitz, M. R., Salmán, E., Jusino, C. M., \& Garfinkel, R. (1994). Ataque de nervios and panic disorder. American Journal of Psychiatry, $15,871-875$.

Lillard, A. (1998). Ethnopsychologies: Cultural variations in theories of mind. Psychological Bulletin, 123, 3-32.

Lipset, S. M. (1996). American exceptionalism: A double-edged sword. New York: Norton.

Lloyd, G. E. R. (1990). Demystifying mentalities. New York: Cambridge University Press.

Lonner, W. (1985). The search for psychological universals. In H. C. Triandis \& W. W. Lambert (Eds.), Handbook of cross-cultural psychology (Vol. 1, pp. 143-204). Boston: Allyn \& Bacon.

Malinowski, B. (1944). A scientific theory of culture and other essays. New York: Oxford University Press.

Markus, H. R., \& Kitayama, S. (1991). Culture and the self: Implications for cognition, emotion, and motivation. Psychological Review, 98, 224253

Masataka, N. (2002). Low anger-aggression and anxiety-withdrawal characteristic to preschoolers in Japanese society with "hikikomori" is becoming a major social problem. Early Education and Development, 13, 187-199.

Masuda, T., \& Nisbett, R. E. (2001). Attending holistically versus analytically: Comparing the context sensitivity of Japanese and Americans. Journal of Personality and Social Psychology, 81, 922-934.
McCrae, R. R., Yik, M. S. M., Trapnell, P. D., Bond, M. H., \& Paulhus, D. L. (1998). Interpreting personality profiles across cultures: Bilingual, acculturation, and peer rating studies of Chinese undergraduates. Journal of Personality and Social Psychology, 74, 1041-1055.

Mead, M. (1928). Coming of age in Samoa: A psychological study of primitive youth for Western civilization. New York: Blue Ribbon Books.

Mead, M. (1975). Review of "Darwin and facial expression." Journal of Communication, 25, 209-213.

Medin, D. L., \& Atran, S. (Eds.). (1999). Folkbiology. Cambridge, MA: MIT Press.

Medin, D. L., \& Atran, S. (2004). The native mind: Biological categorization and reasoning in development and across cultures. Psychological Review, 111, 960-983.

Mehler, J., Jusczyk, P., Lambertz, G., Halsted, N., Bertoncini, J., \& Amiel-Tison, C. (1988). A precursor of language acquisition in young infants. Cognition, 29, 143-178.

Mesquita, B. (2001). Emotions in collectivist and individualist contexts. Journal of Personality and Social Psychology, 80, 68-74.

Miller, J. G. (1984). Culture and the development of everyday social explanation. Journal of Personality and Social Psychology, 46, 961978.

Miller, J. G. (1999). Cultural psychology: Implications for basic psychological theory. Psychological Science, 10, 85-91.

Miller, J. G., \& Bersoff, D. M. (1992). Culture and moral judgment: How are conflicts between justice and interpersonal responsibilities resolved? Journal of Personality and Social Psychology, 62, 541-554.

Miller, K. F., \& Paredes, D. R. (1996). On the shoulders of giants: Cultural tools and mathematical development. In R. J. Sternberg \& T. Ben-Zeev (Eds.), The nature of mathematical thinking (pp. 83-117). Mahwah, NJ: Erlbaum.

Miller, K. F., Smith, C. M., Zhu, J., \& Zhang, H. (1995). Preschool origins of cross-national differences in mathematical competence: The role of number naming systems. Psychological Science, 6, 56-60.

Miyake, K. (1993). Temperament, mother-infant interaction, and early development. The Japanese Journal of Research on Emotions, 1, 48-55.

Morling, B., Kitayama, S., \& Miyamoto, Y. (2002). Cultural practices emphasize influence in the United States and adjustment in Japan. Personality and Social Psychology Bulletin, 28, 311-323.

Morris, M., \& Peng, K. (1994). Culture and cause: American and Chinese attributions for social and physical events. Journal of Personality and Social Psychology, 67, 949-971.

Murdock, G. P. (1945). The common denominator of cultures. In R. Linton (Ed.), The science of man in the world crisis (pp. 123-142). New York: Columbia University Press.

Nakamura, H. (1985). Ways of thinking of eastern peoples. Honolulu, HI: University of Hawaii Press. (Original work published 1964)

Nisbett, R. E. (2003). The geography of thought. New York: Free Press.

Nisbett, R. E., \& Cohen, D. (1996). Culture of honor: The psychology of violence in the south. Boulder, CO: Westview Press.

Nisbett, R. E., \& Norenzayan, A. (2002). Culture and cognition. In H. Pashler \& D. L. Medin (Eds.), Stevens' handbook of experimental psychology: Cognition (Vol. 2, 3rd ed., pp. 561-597). New York: Wiley.

Nisbett, R. E., Peng, K., Choi, I., \& Norenzayan, A. (2001). Culture and systems of thought: Holistic vs. analytic cognition. Psychological Review, 108, 291-310.

Nisbett, R. E., \& Ross, L. (1980). Human inference: The strategies and shortcomings of social judgment. Englewood Cliffs, NJ: Prentice Hall.

Norenzayan, A. (in press). Cultural variation in reasoning. In R. Viale (Ed.), Natural and cultural bases of human inference. Mahwah, NJ: Erlbaum.

Norenzayan, A., \& Atran, S. (2004). Cognitive and emotional processes in the cultural transmission of natural and nonnatural beliefs. In M. Schaller \& C. Crandall (Eds.), The psychological foundations of culture (pp. 149-169). Mahwah, NJ: Erlbaum. 
Norenzayan, A., \& Nisbett, R. E. (2000). Culture and causal cognition. Current Directions in Psychological Science, 9, 132-135.

Norenzayan, A., Smith, E. E., Kim, B., \& Nisbett, R. E. (2002). Cultural preferences for formal versus intuitive reasoning. Cognitive Science, 26, 653-684.

Oishi, S., Diener, E., Lucas, R., \& Suh, E. (1999). Cross-cultural variations in predictors of life satisfaction: Perspectives from needs and values. Personality and Social Psychology Bulletin, 25, 980-990.

Okazaki, S. (1997). Sources of ethnic differences between Asian American and White American college students on measures of depression and social anxiety. Journal of Abnormal Psychology, 106, 52-60.

Okazaki, S., \& Sue, S. (1995). Methodological issues in assessment research with ethnic minorities. Psychological Assessment, 7, 367-375.

Osherson, D. N., Smith, E. E., Wilkie, O., López, A., \& Shafir, E. (1990). Category-based induction. Psychological Review, 97, 185-200.

Paulhus, D. L. (1998). Interpersonal and intrapsychic adaptiveness of trait self-enhancement: A mixed blessing? Journal of Personality and Social Psychology, 74, 1197-1208.

Peng, K., \& Nisbett, R. E. (1999). Culture, dialectics, and reasoning about contradiction. American Psychologist, 54, 741-754.

Peng, K., Nisbett, R. E., \& Wong, N. Y. C. (1997). Validity problems comparing values across cultures and possible solutions. Psychological Methods, 2, 329-344.

Pepitone, A., \& Triandis, H. C. (1987). On the universality of social psychological theories. Journal of Cross-Cultural Psychology, 18, 471498

Piaget, J. (1952). The origins of intelligence in the child. New York: Norton.

Pica, P., Lerner, C., Izard, V., \& Dehaene, S. (2004, October 15). Exact and approximate arithmetic in an Amazonian indigenous group. Science, 306, 499-503.

Pinker, S. (1997). How the mind works. New York: Norton.

Pinker, S., \& Bloom, P. (1992). Natural language and natural selection. In J. H. Barkow, L. Cosmides, \& J. Tooby (Eds.), The adapted mind: Evolutionary psychology and the generation of culture (pp. 451-494). Oxford: Oxford University Press.

Plomin, R., Owen, M. J., \& McGuffin, P. (1994, June 17). The genetic basis of complex human behaviors. Science, 264, 1733-1739.

Polk, T., Stallcup, M., Alsop, D. C., D’Esposito, M., Detre, J. A., \& Farah, M. J. (2002). Neural specialization for letter recognition. Journal of Cognitive Neuroscience, 14, 145-159.

Polka, L., \& Werker, J. (1994). Developmental changes in perception of nonnative vowel contrasts. Journal of Experimental Psychology: Human Perception and Performance, 20, 421-435.

Poortinga, Y. H. (1989). Equivalence of cross-cultural data: An overview of basic issues. International Journal of Psychology, 24, 737-756.

Proffitt, J. B., Coley, J. D., \& Medin, D. L. (2000). Expertise and categorybased induction. Journal of Experimental Psychology: Learning, Memory, and Cognition, 26, 811-828.

Pyszczynski, T., Greenberg, J., \& Solomon, S. (2004). Why do people need self-esteem? A theoretical and empirical review. Psychological Bulletin, 130, 435-468.

Quinones-Vidal, E., Lopez-Garcia, J. J., Penaranda-Ortega, M., \& TortosaGil, F. (2004). The nature of social and personality psychology as reflected in JPSP, 1965-2000. Journal of Personality and Social Psychology, 86, 435-452.

Resnick, L. B. (1994). Situated rationalism: Biological and social preparation for learning. In L. A. Hirschfeld \& S. A. Gelman (Eds.), Mapping the mind: Domain specificity in cognition and culture (pp. 474-494). Cambridge, England: Cambridge University Press.

Rhodes, G., Lee, K., Palermo, R., Weiss, M., Yoshikawa, S., Clissa, P., et al. (2005). Attractiveness of own-race, other-race, and mixed-race faces. Perception, 34, 319-340.
Richerson, P. J., \& Boyd, R. (2004). Not by genes alone: How culture transformed human evolution. Chicago: University of Chicago Press.

Roberson, D., Davidoff, J., Davies, I. R. L., \& Shapiro, L. R. (2004). The development of color categories in two languages: A longitudinal study. Journal of Experimental Psychology: General, 133, 554-571.

Roberson, D., Davies, I., \& Davidoff, J. (2000). Color categories are not universal: Replications and new evidence from a stone-age culture. Journal of Experimental Psychology: General, 129, 369-398.

Roy, M., Neale, M. C., \& Kendler, K. S. (1995). The genetic epidemiology of self-esteem. British Journal of Psychiatry, 166, 813-820.

Rozin, P. (1976). Psychological and cultural determinants of food choice. In T. Silverstone (Ed.), Appetite and food intake (pp. 286-312). Berlin, Germany: Dahlem Konferenzen.

Rozin, P. (2001). Social psychology and science: Some lessons from Solomon Asch. Personality \& Social Psychology Review, 5, 2-14.

Russell, J. A. (1991). Culture and the categorization of emotions. Psychological Bulletin, 110, 426-450.

Russell, J. A. (1994). Is there universal recognition of emotion from facial expression? A review of cross-cultural studies. Psychological Bulletin, $115,102-141$

Ryder, A. G. (2004). Cross-cultural differences in the presentation of depression: Chinese somatization and Western psychologization. Unpublished doctoral dissertation, University of British Columbia.

Sachdev, P. S. (1990). Whakama: Culturally determined behavior in the New Zealand Maori. Psychological Medicine, 20, 433-444.

Sanchez-Burks, J., Lee, F., Choi, I., Nisbett, R., Zhao, S., \& Koo, J. (2003). Conversing across cultures: East-West communication styles in work and nonwork contexts. Journal of Personality and Social Psychology, $85,363-372$.

Schaller, M., \& Crandall, C. (2004). The psychological foundations of culture. Mahwah, NJ: Erlbaum.

Schlegel, A., \& Barry, H., III. (1991). Adolescence: An anthropological inquiry. New York: Free Press.

Schwartz, S. H. (1992). Universals in the content and structure of values: Theoretical advances and empirical tests in 20 countries. Advances in Experimental Social Psychology, 25, 1-65.

Sears, D. O. (1986). College sophomores in the laboratory: Influences of a narrow data base on social psychology's view of human nature. Journal of Personality and Social Psychology, 51, 515-530.

Segall, M. H., Campbell, D. T., \& Herskovits, M. J. (1963, February 22). Cultural differences in the perception of geometric illusions. Science, 193, 769-771

Shavelson, R. J., \& Webb, N. M. (1991). Generalizability: A primer. Newbury Park, CA: Sage.

Shweder, R. (1991). Thinking through cultures: Expeditions in cultural psychology. Cambridge, MA: Harvard University Press.

Shweder, R. (2000). Moral maps, "first world" conceits, and the new evangelists. In L. E. Harrison \& S. P. Huntington (Eds.), Culture matters: How values shape human progress (pp. 158-176). New York: Basic Books.

Shweder, R. (2002, October). The failure of Anthropology 101 and the return of the civilizing project. Public lecture at the University of British Columbia, Vancouver, Canada.

Shweder, R. A., Much, N. C., Mahapatra, M., \& Park, L. (1997). The "big three" of morality (autonomy, community, divinity) and the "big three" explanations of suffering. In A. M. Brandt \& P. Rozin (Eds.), Morality and health (pp. 119-169). New York: Routledge.

Slobin, D. I. (1978). Developmental psycholinguistics. In W. O. Dingwall (Ed.), A survey of linguistic science (pp. 267-311). Stamford, CT: Greylock.

Smith, E. E., Patalano, A. L., \& Jonides, J. (1998). Alternative strategies of categorization. Cognition, 65, 167-196.

Spelke, E. S., Phillips, A., \& Woodward, A. L. (1995). Infants' knowledge of object motion and human action. In D. Sperber, D. Premack, \& A. J. 
Premack (Eds.), Causal cognition: A multidisciplinary debate (pp. 4478). Oxford, England: Oxford University Press.

Sperber, D. (1996). Explaining culture: A naturalistic approach. Cambridge, MA: Blackwell.

Spiro, M. (1987). Culture and human nature. Chicago: University of Chicago Press.

Stich, S. (1990). The fragmentation of reason. Cambridge, MA: MIT Press.

Stigler, J. W. (1984). "Mental abacus": The effect of abacus training on Chinese children's mental calculation. Cognitive Psychology, 16, 145176.

Suh, E. M. (2002). Culture, identity consistency, and subjective well-being. Journal of Personality and Social Psychology, 83, 1378-1391.

Tardif, T. (1996). Nouns are not always learned before verbs: Evidence from Mandarin-speakers' early vocabularies. Developmental Psychology, 32, 492-504.

Taylor, S. E., \& Brown, J. D. (1988). Illusion and well-being: A social psychological perspective on mental health. Psychological Bulletin, 103, 193-210.

Tomasello, M., Kruger, A. C., \& Ratner, H. H. (1993). Cultural learning. Behavioral and Brain Sciences, 16, 495-552.

Triandis, H. (1978). Some universals of social behavior. Personality and Social Psychology Bulletin, 4, 1-16.

Triandis, H. C. (1989). The self and social behavior in differing cultural contexts. Psychological Review, 96, 506-520.

Triandis, H. C. (1995). Individualism and collectivism. Boulder, CO: Westview Press.

Triandis, H. C. (2000). Dialectics between cultural and cross-cultural psychology. Asian Journal of Social Psychology, 3, 185-195.

Turkheimer, E. (2000). Three laws of behavior genetics and what they mean. Current Directions in Psychological Science, 5, 160-164.

Van de Vijver, F., \& Leung, K. (1997). Methods and data analysis of comparative research. In J. W. Berry, Y. H. Poortinga, \& J. Pandey
(Eds.), Handbook of cross-cultural psychology (Vol. 1, pp. 257-300). Boston: Allyn \& Bacon.

Vandello, J. (2004, January). Fewer women, more violence? Examining geographic sex ratios across the United States. Paper presented at the 5th annual conference of the Society of Personality and Social Psychology, Austin, TX.

Vygotsky, L. S. (1978). Mind in society: The development of higher psychological processes. Cambridge, MA: Harvard University Press.

Weissman, M., Bland, R. C., Canino, G. J., Faravelli, C., Greenwald, S., Hwu, H. G., et al. (1996). Cross national epidemiology of major depression and bipolar disorder. Journal of the American Medical Association, 276, 293-299.

Wellman, H. M. (1990). The child's theory of mind. Cambridge, MA: MIT Press.

Wellman, H. M., Cross, D., \& Watson, J. (2001). Meta-analysis of theoryof-mind development: The truth about false belief. Child Development $72,655-684$.

Whorf, B. L. (1956). Language, thought and reality. New York: Wiley.

Winkielman, P., Zajonc, R. B., \& Schwarz, N. (1997). Subliminal affective priming resists attributional interventions. Cognition and Emotion, 11, 433-465.

Wissler, C. (1923). Man and culture. New York: Crowell Company. Zajonc, R. (1965, July 16). Social facilitation. Science, 149, 269-274.

Zajonc, R. (1968). Attitudinal effects of mere exposure. Journal of Personality and Social Psychology, 9(2, Pt. 2).

Zajonc, R. B., Wilson, W. R., \& Rajecki, D. W. (1975). Affiliation and social discrimination produced by brief exposure in day old domestic chicks. Animal Behavior, 23, 131-138.

Received October 8, 2004

Revision received February 21, 2005

Accepted April 8, 2005

\section{Low Publication Prices for APA Members and Affiliates}

Keeping you up-to-date. All APA Fellows, Members, Associates, and Student Affiliates receive-as part of their annual dues-subscriptions to the American Psychologist and APA Monitor. High School Teacher and International Affiliates receive subscriptions to the APA Monitor, and they may subscribe to the American Psychologist at a significantly reduced rate. In addition, all Members and Student Affiliates are eligible for savings of up to $60 \%$ (plus a journal credit) on all other APA journals, as well as significant discounts on subscriptions from cooperating societies and publishers (e.g., the American Association for Counseling and Development, Academic Press, and Human Sciences Press).

Essential resources. APA members and affiliates receive special rates for purchases of APA books, including the Publication Manual of the American Psychological Association, and on dozens of new topical books each year.

Other benefits of membership. Membership in APA also provides eligibility for competitive insurance plans, continuing education programs, reduced APA convention fees, and specialty divisions.

More information. Write to American Psychological Association, Membership Services, 750 First Street, NE, Washington, DC 20002-4242. 